\title{
Assessment of the Integrated Personal Exposure to Particulate Emissions in Urban Micro-environments: A Pilot Study
}

\author{
Phuong Thi Minh Tran, Jie Rui Ngoh, Rajasekhar Balasubramanian* \\ Department of Civil and Environmental Engineering, National University of Singapore, Singapore 117576, Singapore
}

\begin{abstract}
City dwellers' personal exposure to PM is influenced by numerous daily activities in multiple indoor and outdoor micro-environments (MEs). This study assessed the integrated personal exposure to PM across urban MEs together with the recording individual time-activity patterns. We evaluated simultaneously the exposure to $\mathrm{PM}_{2.5}$, black carbon (BC), and ultrafine particles (UFPs) in the Central Business District (CBD) area of Singapore. In addition, we quantified the lung-deposited surface area (LDSA) concentration, which is an indicator of the potential health impacts of UFPs. The field study was conducted over a 7-km walking route to identify air pollution hotspots. Subsequently, the personal exposure to $\mathrm{PM}_{2.5}, \mathrm{BC}$, and UFPs was measured at five selected hotspots for 1 hour each and across indoor and outdoor MEs during diverse daily human activities for 24 hours. The PM concentrations were found to vary considerably in both space and time in the CBD area. During the 1-hour personal exposure measurement, extremely high concentrations of $\mathrm{PM}_{2.5}(215 \pm$ $129.5 \mu \mathrm{g} \mathrm{m}^{-3}$ and $\left.36.4 \pm 12.5 \mu \mathrm{g} \mathrm{m}^{-3}\right)$ and $\mathrm{BC}\left(20.9 \pm 10.4 \mu \mathrm{g} \mathrm{m}^{-3}\right.$ and $\left.18.1 \pm 12.0 \mu \mathrm{g} \mathrm{m}^{-3}\right)$ were observed at a temple and a bus stop, and elevated UFP number concentrations $\left(320.8 \pm 131.1 \times 10^{3} \mathrm{\#} \mathrm{cm}^{-3}\right)$ and high LDSA concentrations $(564.6 \pm$ $276.5 \mu \mathrm{g}^{2} \mathrm{~cm}^{-3}$ ) were measured at a food court. The estimated potential health risk suggests that the continued inhalation of large amounts of $\mathrm{PM}_{2.5}$ emitted from combustion sources is likely to lead to adverse long-term health effects among the exposed individuals. Overall, we provide insight into an individual's total exposure to PM based on time-activity patterns. The results of this work form a scientific basis for developing air pollution control measures to mitigate personal exposure to $\mathrm{PM}$ on a city scale.
\end{abstract}

Keywords: Aerosol sampling and transport; Air quality; Personal exposure.

\section{INTRODUCTION}

Many epidemiological and toxicological studies conducted worldwide indicated that human exposure to high levels of airborne particulate matter (PM), particularly those particles with aerodynamic diameters less than $2.5 \mu \mathrm{m}\left(\mathrm{PM}_{2.5}\right)$, can have adverse human health effects (Pope et al., 1995; WHO, 2013; Kim et al., 2015). The continued exposure to PM is ranked as one of the leading causes of increased morbidity and mortality worldwide (Gakidou et al., 2017). In recent years, the focus of several air pollution studies has shifted from $\mathrm{PM}_{2.5}$ mass concentration to more specific metrics such as the mass concentration of black carbon (BC) and ultrafine particles (UFPs) due to their strong association with negative health effects (e.g., Heal et al., 2012; Wu et al., 2015). BC, a light-absorbing component of PM, is a good indicator of exposure to harmful particulate-bound

\footnotetext{
* Corresponding author.

Tel.: 65-6516 5135; Fax: 65-6779 1635

E-mail address: ceerbala@nus.edu.sg
}

chemical substances such as polycyclic aromatic hydrocarbons (PAHs) emitted from incomplete combustion of fossil fuels. In densely populated areas, the contribution of urban traffic to BC and UFPs is often considered to be more important than that of other fossil fuel combustion activities, including industry (Liu et al., 2005). UFPs (PM with aerodynamic diameter less than $0.1 \mu \mathrm{m}$ ) may be more toxic than $\mathrm{PM}_{2.5}$ due to their enhanced pulmonary deposition efficiency, much higher surface area (in terms of equal mass basis), and a greater proportion of volatile organic compounds in them (Delfino et al., 2005).

Fixed air quality monitoring stations, equipped with often expensive and bulky automated instruments, are widely used to measure PM levels with sufficient time resolution to study the temporal variability of air pollutant concentrations. Measured PM concentrations are required to be below the international air quality benchmarks such as the World Health Organization (WHO) guidelines to protect public health. However, recent studies have indicated that even at a concentration below current air quality regulations (e.g., Environmental Protection Agency (EPA) regulations), health effects persist (Wellenius et al., 2012; Rice et al., 2013). Furthermore, the concentrations of air pollutants are 
subject to high variability in space and in time depending on variations of emission sources, meteorology, land use, and topography (Wilson and Zawar-Reza, 2006). Therefore, fixed air quality monitoring stations do not provide spatially representative PM data for health risk assessment (Kaur et al., 2005). Mobile and cost-effective PM instruments have been recently developed to overcome these problems. Significant improvements in sensing techniques have enabled researchers to investigate personal exposures to a variety of airborne contaminants in a high temporal and spatial resolution measurement (Vincent, 2012; Koehler and Peters, 2015). Accurate assessment of human exposure to PM, including $\mathrm{PM}_{2.5}$, UFPs, and $\mathrm{BC}$, is, therefore, crucial for a proper determination of possible links between particulate air pollution in cities and human health effects.

On average, people spend less than $8 \%$ of their time in urban transport environments, but the urban transport contributes to over $20 \%$ of their daily integrated exposure, leading to many adverse health effects (Dons et al., 2012). Therefore, most of the PM studies using portable devices have focused mainly on the human exposure while in transit and on the influence of different transport modes on exposure outcomes (e.g., Chan et al., 2002; Moreno et al., 2015; Good et al., 2016; Rivas et al., 2017; Shirmohammadi et al., 2017). Selected studies related to personal exposure to $\mathrm{PM}$ in transport micro-environments (MEs) using portable monitors are summarized and given in Table S3. In recent years, active modes of transport such as walking and cycling are receiving increased attention to reduce car dependence. Increased levels of physical activity associated with active modes of transport lead to potential public health benefits (Reynolds et al., 2010). However, some studies showed higher exposure to $\mathrm{PM}_{2.5}$ during walking compared to other commuting modes because of emissions of PM in close proximity, higher inhalation parameters (such as respiratory rate and volume) and longer commuting time (Liu et al., 2015; Betancourt et al., 2017). Apart from transport, city dwellers' personal exposure to air pollution is also influenced by other activities in multiple indoor and outdoor MEs on a daily basis. The characteristics and contributions of these MEs to the daily personal exposure in urban areas are not well understood. In addition, the personal exposure depends on physical health factors (e.g., gender, age, and body weight) and time-activity patterns of individuals. The integrated assessment of health risks associated with inhalation of PM across diverse MEs over 24 hours of exposure needs to be examined on a day-to-day basis. In this regard, using a mobile platform paired with real-time PM monitors and global positioning system (GPS) tracking is a powerful approach to accurately characterize individuals' exposure.

In this pilot field study, two university students (nonsmoking individuals) assessed their personal exposure to $\mathrm{PM}_{2.5}$, UFPs, and BC using portable devices and a GPS in the Central Business District (CBD) area of Singapore. In addition, they quantified the lung-deposited surface area (LDSA) concentration, which is considered to be an appropriate indicator of potential health impacts (Ntziachristos et al., 2007; Albuquerque et al., 2012).
Elevated levels of LDSA are considered to be indicative of adverse health effects such as lung airway inflammation (Buonanno et al., 2013) or acute respiratory visits to an ambulatory medical facility (Sinclair and Tolsma, 2004). The students walked around a range of outdoor and indoor MEs as part of their daily routines. The specific aims of this work were: (1) to characterize the spatio-temporal patterns of the personal exposure to $\mathrm{PM}_{2.5}$, UFPs, and $\mathrm{BC}$ and identify pollution hotspots; (2) to quantify the emission profiles of these pollutants in the identified hotspots; and (3) to estimate potential health risks associated with $\mathrm{PM}_{2.5}$ inhalation over the 24-hour daily exposure. The city-state of Singapore was selected for this study as it is one of the most densely populated cities in the world and has a number of sources of airborne particles due to rapid urbanization and industrialization, large traffic volume, and frequent occurrence of transboundary smoke haze episodes (Kalaiarasan et al., 2009a, b; Huang et al., 2016; Sharma and Balasubramanian, 2017). The Singaporean government is currently promoting active mobility among commuters (i.e., "Walk Cycle Ride" modes) as part of its ongoing efforts towards sustainable development. The preliminary findings obtained can be useful for citizens to make informed choices to reduce their PM exposures while being involved in a range of outdoor and indoor activities on a daily basis. The results will also be useful for the local government to identify and implement effective mitigation measures to lower people's exposure to PM on the city scale, contributing to improved urban air quality and enhanced health benefits.

\section{METHODS}

\section{Study Location and Design}

The personal exposure assessment to PM was conducted in the CBD area of Singapore between October 2017 and February 2018. This area attracts tourists and contains multiple street canyons amidst high-rise buildings representative of the urban landscape. The average traffic volume entering the CBD area is 300,400 vehicles day ${ }^{-1}$, and the average speed of vehicles in the area is $28.9 \mathrm{~km} \mathrm{~h}^{-1}$ during peak hours (Govtech-Singapore, 2018). Other than traffic, major sources of air pollution in this area comprise commercial cooking activities in restaurants and food courts, construction activities, smoking in the open area, and incense or joss paper burning in temples. Fig. 1 provides an aerial overview of the study area.

The field study was divided into three separate components: the first component of the study was carried out over a 7-km walking route around the CBD area to study both temporal and spatial variations of PM concentrations. The second component quantified PM exposure levels in five pollution hotspots. The third one measured the 24-hour personal $\mathrm{PM}_{2.5}$ exposure under a range of diverse daily human activities across indoor and outdoor MEs.

\section{Sub-study 1: 7-km Walking Route Measurements}

A 7-km walking route around the CBD was chosen that covered many land uses and different road categories 


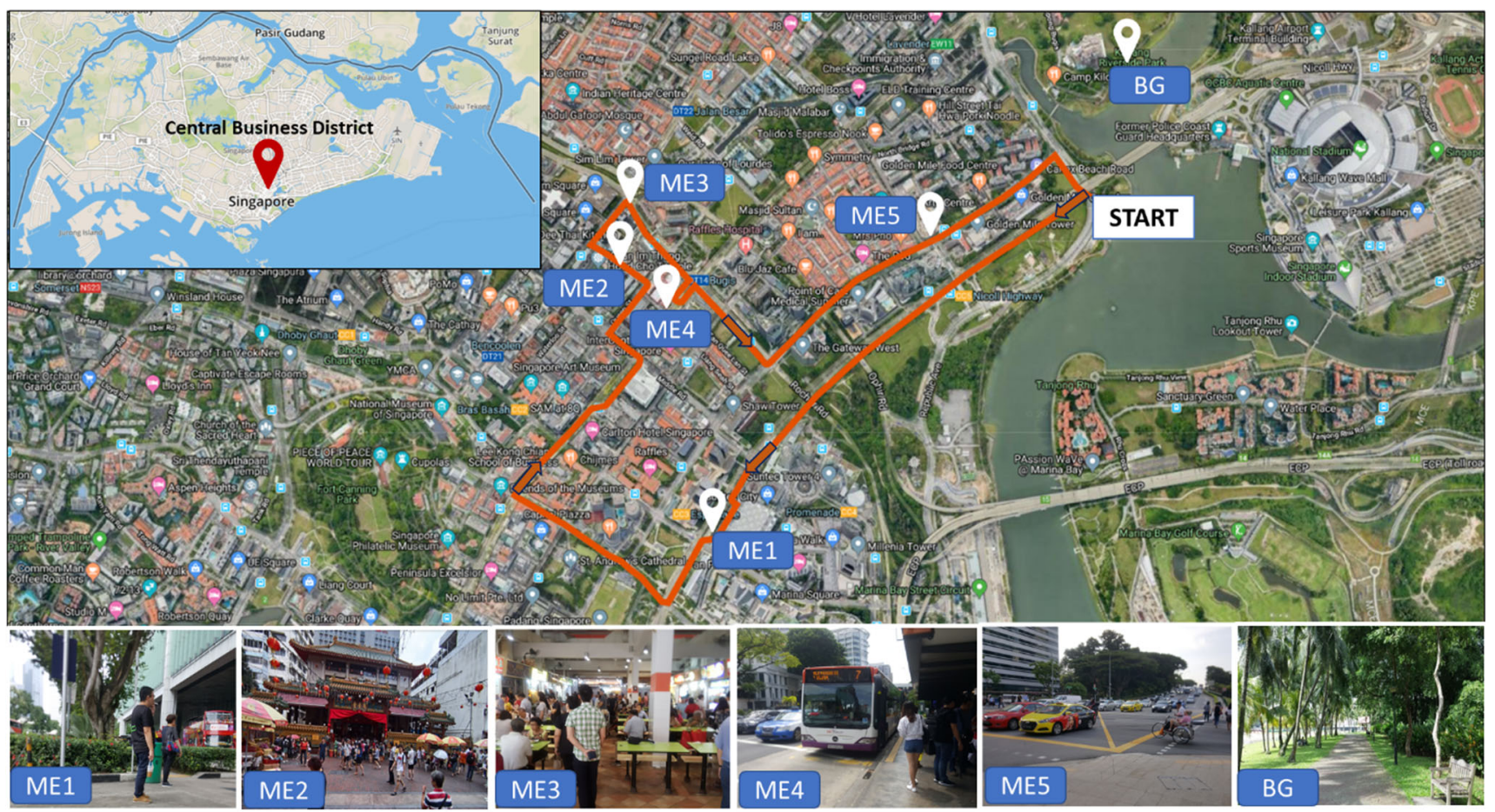

Fig. 1. 7-km walking route around the $\mathrm{CBD}$ area with five selected micro-environments and background location. The map was generated from Google Maps.

(highways, major arterial roads, minor arterial roads, primary access, and local access). The students walked over the pedestrian footpaths along the designated route across diverse indoor and outdoor MEs. Exposure pathways are shown in Fig. 1. The study was conducted on typical weekdays (i.e., Tuesday-Thursday) and weekends (i.e., Saturday-Sunday) during the morning (07:30-10:00), afternoon (11:30-14:00), and evening (18:00-20:30). These time periods were selected to investigate the personal exposure under different levels of human activities in the CBD. In total, 19 personal exposure assessments were conducted over the $7-\mathrm{km}$ route $(\sim 2.5$ hours per walking trip) around the CBD area. A 7-hectare public park located to the east of the study site was selected as the background location (BG), which is relatively clean compared to the $\mathrm{CBD}$ due to the absence of combustion-related sources. Personal exposure data were also collected in the BG location with the same protocol as used in the CBD area.

\section{Sub-study 2: 1-hour Personal Exposure Measurements at Selected Air Pollution Hotspots}

Five diverse outdoor and indoor MEs (including a smoking area, a temple, a food court (hawker center), a bus stop, and a traffic intersection) were selected (based on the observations made in Sub-study 1) to better understand the typical emission profiles in response to the nature and intensity of human activities in the specific locations. The characteristics of these MEs are described in Table 1. In total, 28 monitoring studies were conducted in the MEs over a duration of 1 hour on weekdays during morning, afternoon, and evening time periods.

\section{Sub-study 3: 24-hour personal Exposure Measurements}

$\mathrm{PM}_{2.5}$ mass concentrations were only considered in the 24-hour personal exposure assessment as they are routinely measured by the National Environment Agency (NEA) as one of the six criteria air pollutants at fixed monitoring stations throughout Singapore. To determine the inhaled dose of $\mathrm{PM}_{2.5}$, 24-hour personal exposure studies were conducted for 4 days. For this work, a portable $\mathrm{PM}_{2.5}$ monitor was used throughout the daily routine of the students for the entire day. During each sampling day, the student visited the common MEs as in the previous substudies (i.e., bus stops, traffic intersections, and the hawker center) and followed similar time-activity patterns over the 4 days to maintain consistency. The students noted their whereabouts in a time-activity diary, and a GPS receiver was used to identify the specific MEs visited at different times of the day.

\section{Instrumentation and quality Assurance}

The PM measurements included (1) the mass concentration of $\mathrm{PM}_{2.5}\left(\mu \mathrm{g} \mathrm{m}^{-3}\right)$, (2) the number concentration of UFPs $\left(\mathrm{Np} ; \#_{\mathrm{cm}^{-3}}\right.$ ), (3) the lung-deposited surface area (LDSA; $\mu \mathrm{g}^{2} \mathrm{~cm}^{-3}$ ), and (4) the mass concentration of black carbon $\left(\mathrm{BC} ; \mu \mathrm{g} \mathrm{m}^{-3}\right)$. The mass concentration of $\mathrm{PM}_{2.5}$ was measured using a light-scattering laser photometer (SidePak AM520; TSI Inc., USA). Np and LDSA were measured using a handheld particle counter (DiSCmini; Testo, Germany). The mass concentration of $\mathrm{BC}$ was measured by a microaethalometer (microAeth AE51; Aethlabs, USA). Also, relative humidity $\mathrm{RH}(\%)$ and temperature $\mathrm{T}\left({ }^{\circ} \mathrm{C}\right)$ were measured using temperature and humidity loggers (BGLog-TempRH; Acez, Singapore). A GPS receiver was 
Table 1. Characteristics of micro-environments at the study location.

\begin{tabular}{|c|c|c|}
\hline \multicolumn{2}{|c|}{ Micro-environments } & Characteristics \\
\hline ME1 & Outdoor smoking area & $\begin{array}{l}\text { Stay on Nicoll Highway. In front of Suntec City shopping mall. } \\
\text { There were about } 6-10 \text { smokers in the morning and 5-8 smokers } \\
\text { in the afternoon and evening hours on observed days. }\end{array}$ \\
\hline ME2 & Kwan Im Thong Hood Cho Temple & $\begin{array}{l}\text { Buddhist temple. } \\
\text { Prayer area with elevated incense smoke. } \\
\text { Measurement location was at the courtyard of the temple, about } \\
3 \mathrm{~m} \text { from the temple. } \\
\text { Closed at night. }\end{array}$ \\
\hline ME3 & Hawker center & $\begin{array}{l}\text { An open-air complex selling a whole range of food. } \\
\text { There were about } 20 \text { food stalls. }\end{array}$ \\
\hline ME4 & $\begin{array}{l}\text { Opp Bugis Junction } \\
\text { Bus stop (identification number: 01112) }\end{array}$ & $\begin{array}{l}12 \text { bus services daily. } \\
7 \text {-lane road, with a bus lane. }\end{array}$ \\
\hline ME5 & Traffic intersection & 4-way intersection crossing over Beach Road and Ophir Road. \\
\hline
\end{tabular}

used to track the movement and exposure of the subjects across the MEs during the study period. Table S1 provides the characteristics of each device.

The SidePak is a real-time laser photometer that detects $\mathrm{PM}_{2.5}$ and quantifies its mass concentration based on the light scattering of aerosols. The device was operated with a flow rate of $1.7 \mathrm{~L} \mathrm{~min}^{-1}$ which was verified before the sampling with a flowmeter (Model 4100; TSI Inc.). The SidePak was factory-calibrated to the respirable fraction of standard ISO 12103-1, A1 Arizona Test Dust. To get reliable $\mathrm{PM}_{2.5}$ mass concentrations that are representative of the specific sampling locations, the SidePak was further calibrated with a gravimetric sampler (MiniVol; Airmetrics, USA). Calibration factors of 0.22 and 0.19 were applied to the $\mathrm{PM}_{2.5}$ concentrations obtained from the two SidePak units to get the final $\mathrm{PM}_{2.5}$ concentrations. Detailed steps involved in the calibration of the SidePak are described in supplementary material (SM) section 2.

The DiSCmini is a handheld particle counter that operates based on the diffusion charging principle. Particles are charged by a unipolar diffusion charger and the current is measured by an electrometer as the particles pass through the designed diffusion and filter stage in the instrument chamber. The current difference between the two stages is measured to obtain the total UFP Np and the average particle size. The DiSCmini also measured alveolar LDSA, which is defined as the particle surface area weighted by the deposition efficiency of airborne particles in the alveoli region based on a model proposed by the International Commission for Radiological Protection (ICRP, 1994). Very good agreements were observed when the performance of the DiSCmini was compared to that of condensation particle counters in previous studies (Asbach et al., 2012; Meier et al., 2013). An impactor provided by the manufacturer was always equipped at the inlet of the DiSCmini to prevent PM larger than $0.7 \mu \mathrm{m}$ from entering into the device.

The BC concentration was quantified by a microAeth AE51, which measures the attenuation of light transmitted through airborne particles that are continuously collected onto a Teflon filter. In the present study, filter strips were changed every 5 hours of air sampling to minimize filter loading effects. Before air sampling, the two microAeth units were calibrated side by side using a TSI flowmeter, following the auto-flow calibration procedure recommended by the manufacturer. The microAeth was operated with the

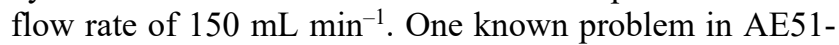
based measurements is that at high logging intervals or very low $\mathrm{BC}$ values, the incremental change in light absorption may be affected by the instrumental noise, leading to negative or unchanging values in the recorded data (Hagler et al., 2011). To resolve this issue, the raw $\mathrm{BC}$ was corrected using the Optimized Noise-Reduction Algorithm (ONA) tool (Hagler et al., 2011) with delta attenuation thresholds of $0.01-0.05$. The second issue associated with the operation of AE51 is the filter loading effect, which affects $\mathrm{BC}$ measurements by the decreasing instrumental sensitivity associated with the increased filter loading. To account for this issue, $\mathrm{BC}$ concentrations were adjusted using an empirical correction factor reported by Kirchstetter and Novakov (2007) based on the optical attenuation (ATN) measured by the instrument. The performance of AE51 was further checked by collocating it with Aethalometer AE33 (Magee Scientific, USA) and doing BC measurements over a period of 24 hours. A correction factor based upon the slope of the linear regression equation obtained from the inter-comparison study was finally applied to the data measured by the microAeth (the data are shown in Fig. S2).

SidePak and DiSCmini were synchronized and programmed to capture data with a time resolution of 1 second. The AE51 was programmed to capture BC data with a time averaging of 10 seconds, whereas temperature and relative humidity, and GPS data were collected at 30second, and 1-minute readings, respectively, as the highest logging intervals set up by the manufacturers. All portable devices were carried in a backpack, and air sampling inlets were placed within the breathing zone at approximately $1.5 \mathrm{~m}$ above the ground level. All the measurements were conducted between October 2017 and February 2018. During this time period, Singapore experienced strong winds with speeds in the range of 7 to $9 \mathrm{~m} \mathrm{~s}^{-1}$ and wet conditions on several occasions (Meteorological Service Singapore) which help in the efficient dispersion of air 
pollutants and their removal from ambient air through wet deposition. It should be noted that all the personal exposure measurements were conducted on hot and sunny days with clear skies to protect the operational integrity of sensors and to avoid the potential measurement issues related to the PM concentrations, caused by high relative humidity and rainfall. A duplicate set of SidePak, DiSCmini, and microAeth was operated at the background site during the collection of the mobile measurements.

Before each day of air sampling, all instruments were clock-synchronized using a laptop connected to the internet to ensure that the time stamp was consistent across all instruments. When arriving at the measurement site, instruments were zeroed with HEPA-filtered air and left to log data for about 5-10 minutes before the actual sampling. Collected data were imported and analyzed mainly using R (R Core Team, 2018) and Microsoft Excel.

\section{Fixed Reference Monitoring Sites}

1-hour-averaged $\mathrm{PM}_{2.5}$ data were obtained from the air quality monitoring station in the central part of Singapore, maintained by the National Environmental Agency (NEA) website (http://www.nea.gov.sg), and analyzed to determine the difference in the assessment of exposure to $\mathrm{PM}_{2.5}$ based on measurements at a fixed location versus those across diverse MEs with mobile devices. In addition, as BC is not routinely monitored by NEA, a multiple-length Aethalometer AE33, located at the Atmospheric Research Laboratory in the National University of Singapore (NUS) campus, was used for the routine measurement of BC. A flow rate of 3 $\mathrm{L}$ min $^{-1}$ was used with a sampling time base of 60 seconds. The determination of the $\mathrm{BC}$ concentration is based on the measurement of light absorption on a filter loaded with aerosols. The AE33 is advantageous in the sense that it can reduce the filter loading effect by utilizing a "dual-spot" measurement method (Drinovec et al., 2015).

\section{Exposure Assessment}

The integrated inhalation dose of $\mathrm{PM}_{2.5}$ was calculated as the sum of exposure for all MEs (n) visited by the students over a specific period of time $(\mathrm{t})$ with the inhalation rate (IR) (Eq. (1)). IR was assumed to be $1.3 \times 10^{-2} \mathrm{~m}^{3} \mathrm{~min}^{-1}$ $\left(=0.78 \mathrm{~m}^{3} \mathrm{~h}^{-1}=18.72 \mathrm{~m}^{3}\right.$ day $\left.^{-1}\right)$ selected from the U.S. EPA's Exposure Factor Handbook-Table 6.17 (Moya et al., 2011) for young adults aged 21-31 years with light activity levels.

$$
\begin{aligned}
& \text { Integrated } \mathrm{PM}_{2.5} \text { inhaled dose }(\mu \mathrm{g})= \\
& \sum_{i=1}^{n}\left(\text { Mass Concentration } \mathrm{C}_{\mathrm{i}}\left(\frac{\mu \mathrm{g}}{\mathrm{m}^{3}}\right) \times\right. \\
& \left.\left.\times \text { Inhalation Rate } \mathrm{IR}\left(\frac{\mathrm{m}^{3}}{\text { hour }}\right) \times \text { Exposure Time } \mathrm{t}_{\mathrm{i}} \text { (hours }\right)\right)
\end{aligned}
$$

The integrated inhaled dose of $\mathrm{PM}_{2.5}$ based on measurements using the SidePak was then compared to those obtained from fixed ambient air monitoring stations maintained by NEA for the respective days. Moreover, the toxicological health risk associated with chronic exposure to $\mathrm{PM}_{2.5}$ was quantified as the risk quotient (RQ). The steps involved to estimate the lifetime average daily dose (LADD) and toxicological RQ to $\mathrm{PM}_{2.5}$ are described in SM section 4.

\section{RESULTS AND DISCUSSION}

\section{General Characteristics of PM Exposure around 7-km Walking Route around Central Business District}

The observed personal PM exposure concentrations varied considerably in both space and time at the CBD area. Fig. 2 presents the variations in $\mathrm{PM}_{2.5}, \mathrm{BC}, \mathrm{Np}$, and LDSA exposure concentrations observed during weekdays and weekends in the study area. The statistical data are summarized in Table S2. During weekdays, the mean $\mathrm{PM}_{2.5}$ concentrations were $46.2,35.3$, and $22.2 \mu \mathrm{g} \mathrm{m} \mathrm{m}^{-3}$ in the morning, afternoon, and evening hours, respectively; the overall mean concentration was $32.5 \mu \mathrm{g} \mathrm{m}^{-3}$. Our study reveals that the $\mathrm{PM}_{2.5}$ concentrations were the lowest in the study area during the evening hours, which is attributed to changes in the traffic composition and in PM sources during the day. Specifically, there was a large volume of buses, taxis, and cars during morning and afternoon hours while a relatively high number of trucks and utility vehicles were during the afternoon hours. Additionally, other PM sources such as construction activities and incense burning were carried out only during the day. The changes in the tropical weather conditions during the day also played an important role in affecting the $\mathrm{PM}_{2.5}$ concentrations in the study area. No significant difference was found in the $\mathrm{PM}_{2.5}$ exposure between weekdays and weekends at the CBD area except in the morning session. Vehicular emissions contributed more to the ambient PM on weekdays in the morning (46.2 $\mu \mathrm{g} \mathrm{m}^{-3}$ ) as compared to the weekends $\left(34.8 \mu \mathrm{g} \mathrm{m}^{-3}\right)$.

All the PM concentration values were much higher than those measured in the urban background due to the presence of many sources of air pollution along the measurement route. For example, the mean $\mathrm{PM}_{2.5}$ concentrations were $34.8,33.2$, and $24.7 \mu \mathrm{g} \mathrm{m}^{-3}$ on weekends in the morning, afternoon, and evening hours compared to 10.2, 9.9, and $11.9 \mu \mathrm{g} \mathrm{m}^{-3}$ at the background site, respectively. In the case of BC, the mean concentration observed in the studied area was $8.0 \mu \mathrm{g} \mathrm{m}^{-3}$ (about $24.5 \%$ contribution to $\mathrm{PM}_{2.5}$ ) at the CBD area compared to $3.2 \mu \mathrm{g} \mathrm{m}^{-3}$ measured at the background location. High concentrations of $\mathrm{BC}$ indicate the dominant contributions of the local traffic and incense burning activities at the study area. In the present study, UFPs were quantified by $\mathrm{Np}$ and LDSA. In general, the measured values were $62.4 \times 10^{3} \mathrm{\#} \mathrm{cm}^{-3}$ (ranging between 42.8 and $82.3 \times 10^{3} \mathrm{H} \mathrm{cm}^{-3}$ ) and $125.5 \mu \mathrm{g}^{2} \mathrm{~cm}^{-3}$ (ranging between 71.6 and $179.7 \mu \mathrm{g}^{2} \mathrm{~cm}^{-3}$ ) of $\mathrm{Np}$ and LDSA concentrations, respectively, at the CBD area. These UFP concentrations were about 4 times higher than those measured at the background location. As the commercial areas (e.g., hawker centers) become more active towards weekends, higher UFP levels were observed during weekends compared to weekdays (as shown in Figs. 2(c)-2(d) and Table S2). 


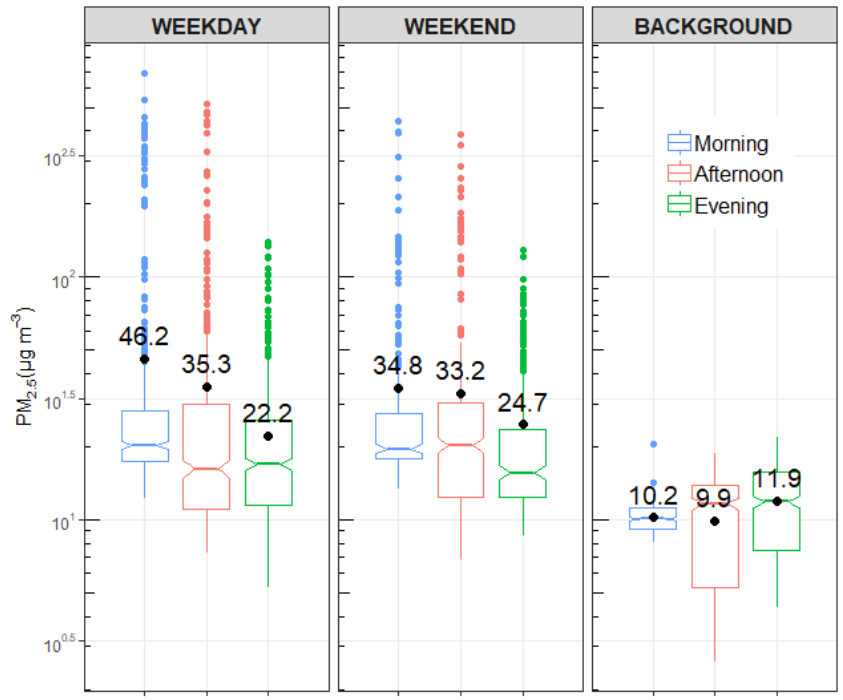

(a)

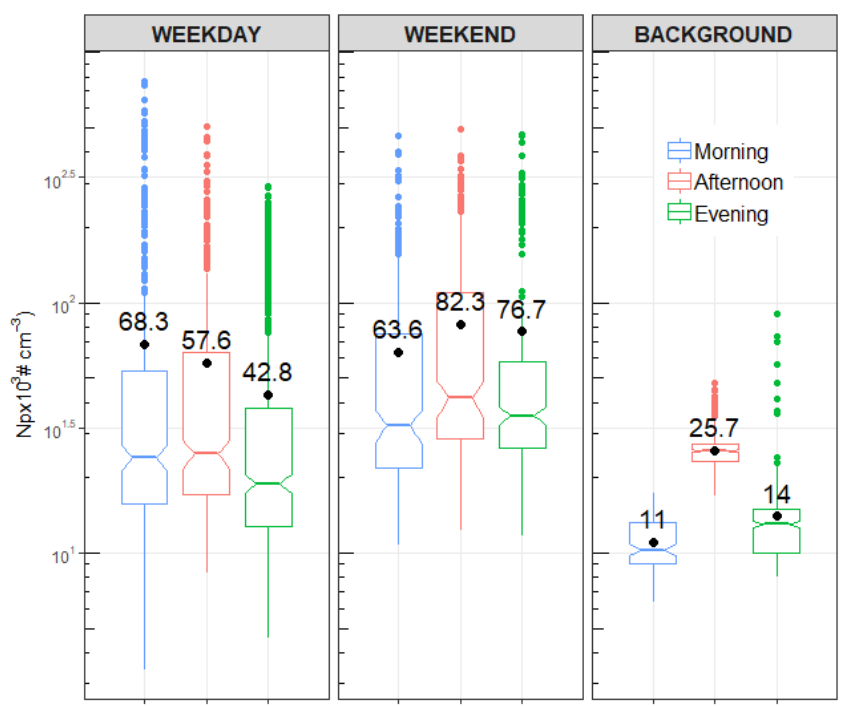

(c)

Fig. 2. Personal exposure concentrations of (a) $\mathrm{PM}_{2.5}$, (b) BC, (c) Np, and (d) LDSA during weekdays and weekends at the $\mathrm{CBD}$ area compared to the background location.

The distributions of PM concentrations are highly skewed, especially for UFPs and LDSA as shown in Fig. 2, suggesting a high spatio-temporal variability of PM during the field trips. Also, all mean values of particle metrics were higher than the median due to the presence of exceedances (i.e., outliers) that increased the mean but did not affect the median. These outliers were mainly associated with incense burning emissions and/or exhaust plumes of on-road vehicles under acceleration or deceleration. Elevated concentrations of PM (e.g., $\mathrm{PM}_{2.5}>150 \mu \mathrm{g} \mathrm{m}^{-3}$; $\mathrm{BC}>10 \mu \mathrm{g} \mathrm{m}^{-3}$; $\mathrm{Np}>50$

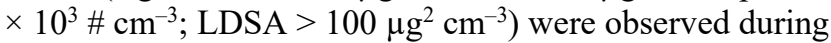
most of the personal exposure measurements. Although these spike concentrations are temporal (i.e., short-term exposure), they still contribute to personal pollution exposure to trigger the onset of myocardial infarction (Peters et al., 2001; Peters et al., 2004) or systemic and pulmonary inflammatory responses (Salvi et al., 1999), so we retained

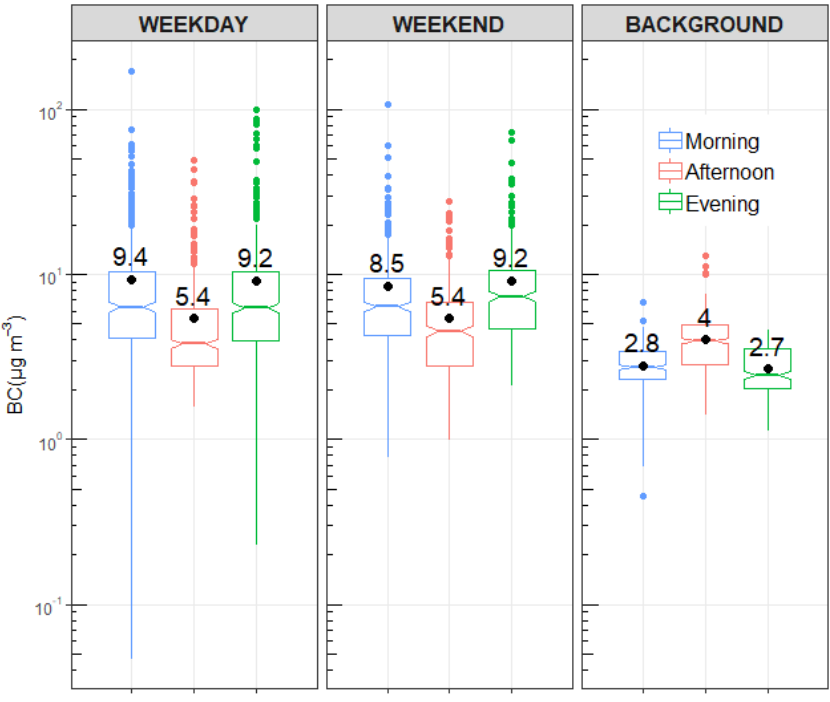

(b)

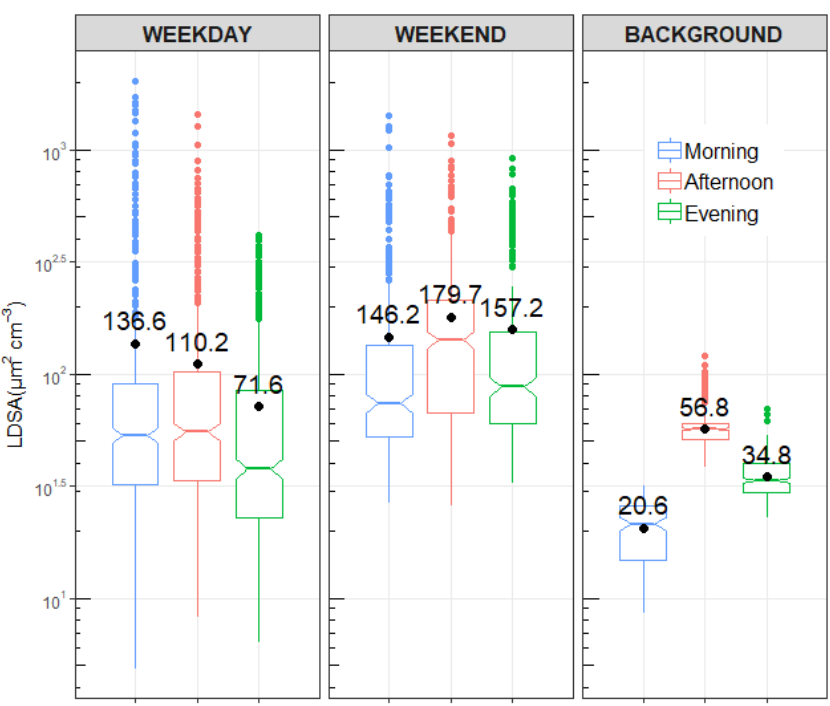

(d) these concentration values.

The representative exposure pathways within CBD are presented in Figs. 3 and S3 for the morning session. Both time series (Fig. 3) and spatial PM maps (Fig. S3) show the actual exposure to PM under different pollution conditions; the data were aggregated for every minute on representative days. $\mathrm{PM}_{2.5}$ concentrations were generally homogeneous (Fig. 3(a)) compared to the heterogeneous spatial distributions of BC (Fig. 3(b)) and UFPs (Figs. 3(c) and 3(d)) over the length of the route. The lack of spatial variations on $\mathrm{PM}_{2.5}$ can be explained by the relatively long atmospheric residence time of fine particles (Thai et al., 2008). In contrast, UFPs showed a heterogeneous spatial distribution due to the occurrence of nucleation and coagulation processes under ambient tropical weather conditions (e.g., high relative humidity and temperature). Their concentrations can drop to their background levels in open terrains approximately 
$300 \mathrm{~m}$ from a source (Klompmaker et al., 2015). BC with its small particle size (i.e., nanometers in diameter) showed a spatial variation similar to that of UFPs, but it was much larger than that of $\mathrm{PM}_{2.5}$ (WHO, 2012). Significant peaks in PM concentrations measured along the route are shown in Fig. 3. The highest concentrations of $\mathrm{PM}_{2.5}$ and $\mathrm{BC}$ were observed at the temple and traffic-influenced locations, while the hawker center and the temple had the extremely high concentration of UFPs.

Ambient temperature and relative humidity were also continuously measured (Table S2). The temperature ranged from 25.6 to $35.3^{\circ} \mathrm{C}$ during the measurement days, and the mean temperature was $30.0 \pm 2.0^{\circ} \mathrm{C}$. Among the five selected MEs, the marked temperature values were recorded at the temple and traffic-related locations with mean values of 33.2 and $32.3^{\circ} \mathrm{C}$ (data not shown). The relative humidity generally ranged between $50 \%$ and $85 \%$ in the study area, and the mean value was $68.6 \pm 7.9 \%$.

\section{1-hour Personal Exposure Measurements at Five Air Pollution Hotspots}

To better understand the typical emission profiles of PM in response to the nature and intensity of human activities in specific locations, 1-hour personal exposure measurements were conducted at five selected MEs three times a day (i.e., morning, afternoon, and evening; Fig. 4). These measurements were repeated twice at each $\mathrm{ME}$ on different days. The measured exposure concentrations of $\mathrm{PM}_{2.5}, \mathrm{BC}$,

(a)

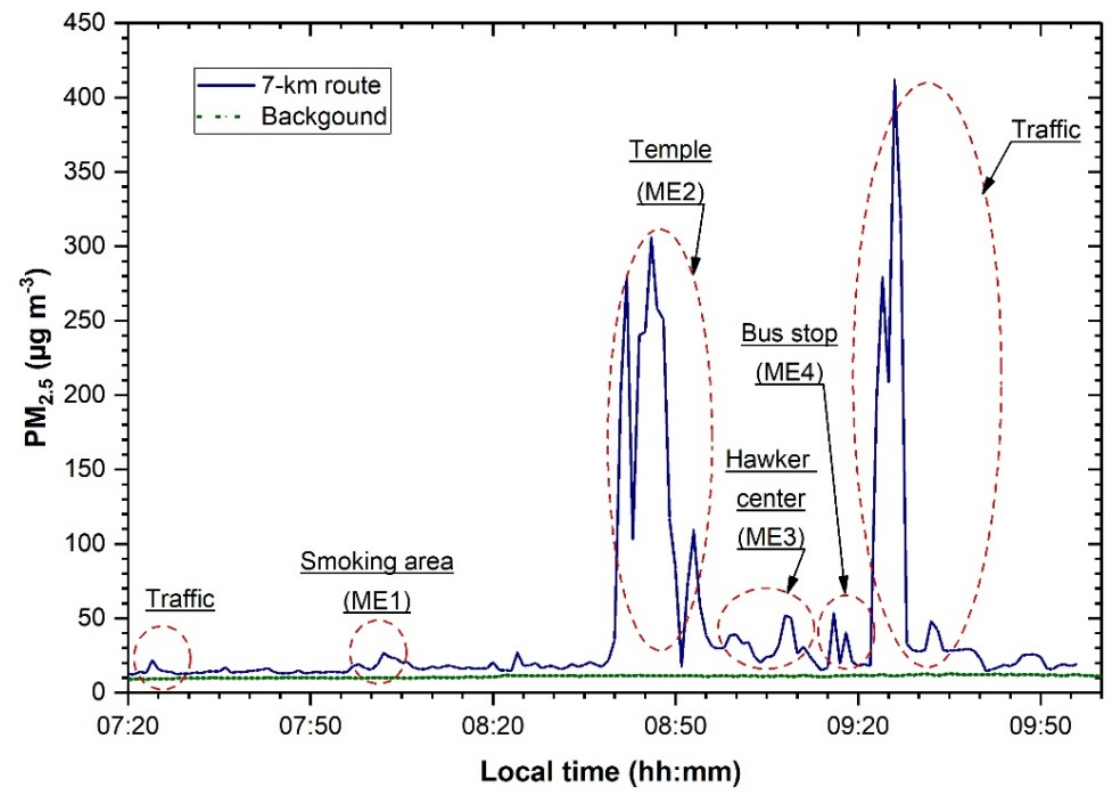

(b)

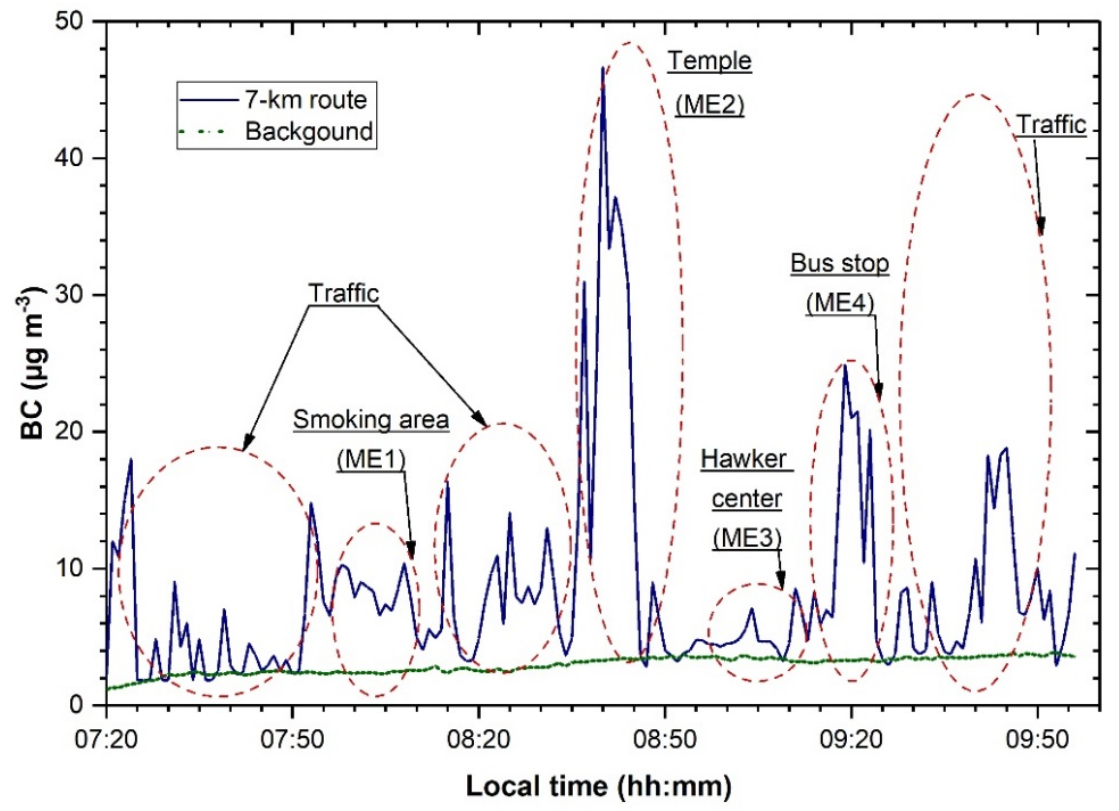

Fig. 3. Time series of (a) $\mathrm{PM}_{2.5}$, (b) BC, (c) Np, and (d) LDSA. The measurements were conducted on 2 Jan. 2018 during morning hours. 
(c)

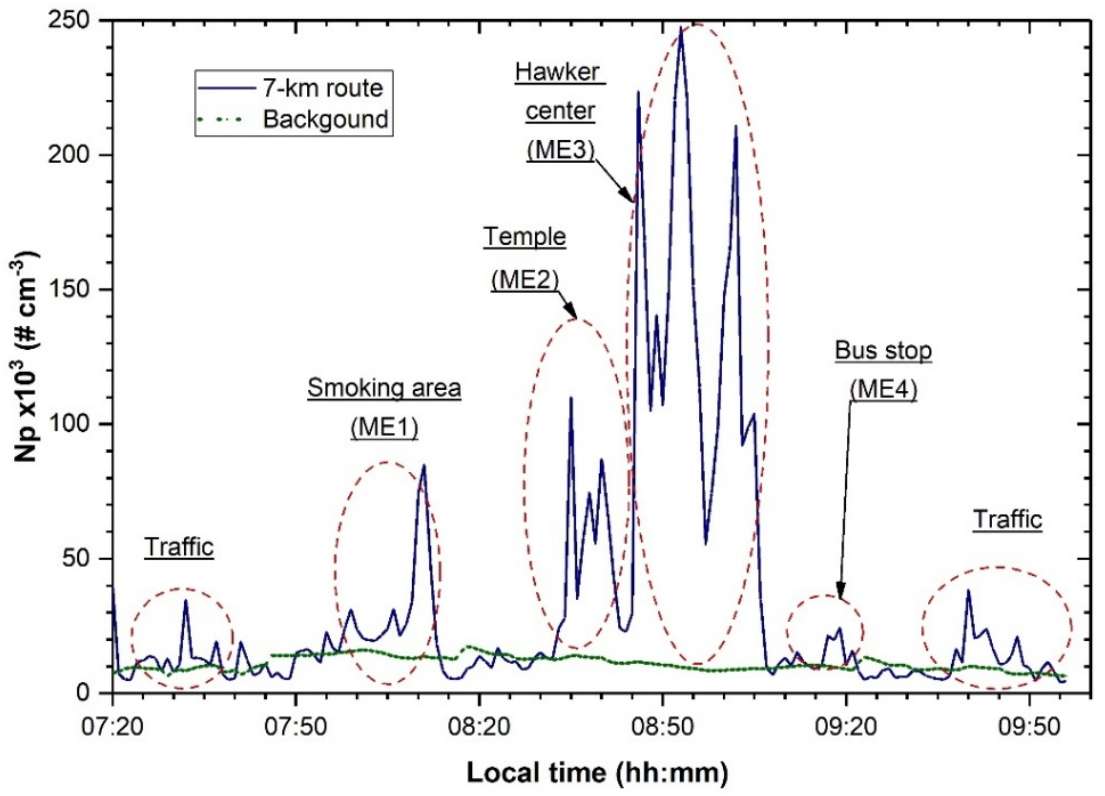

(d)

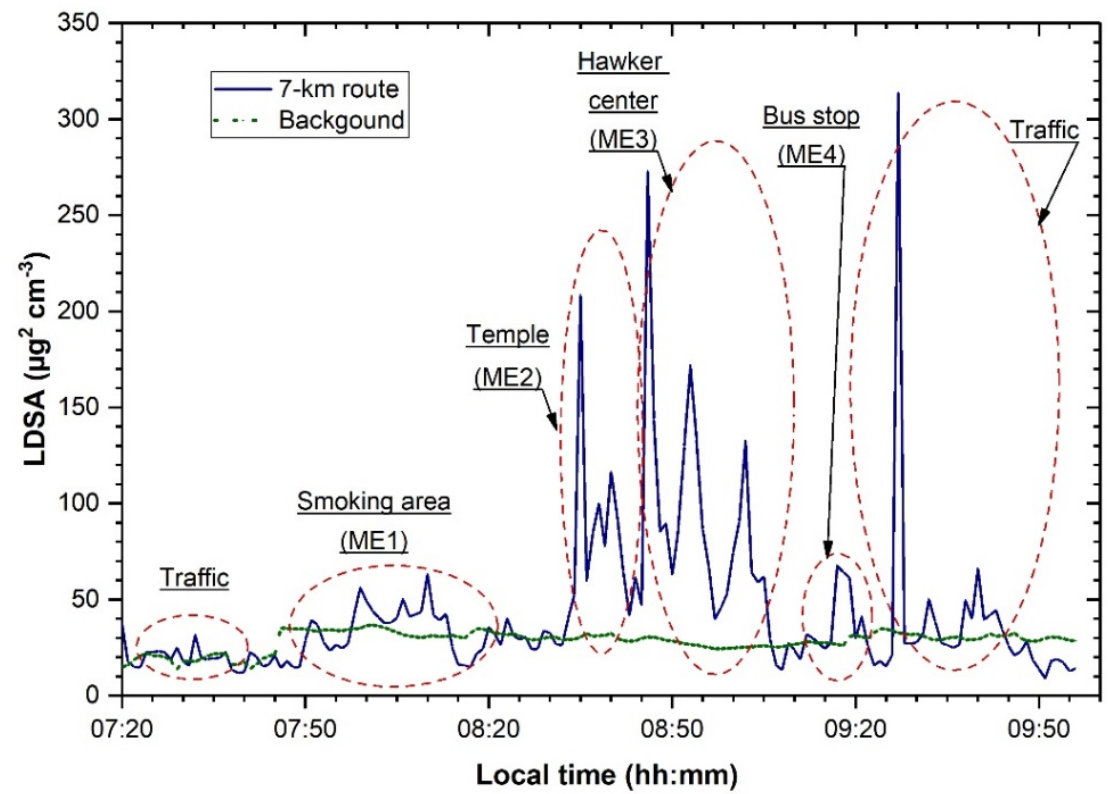

Fig. 3. (continued).

$\mathrm{Np}$, and LDSA were much higher than those measured at the fixed monitoring stations (the NEA air quality monitoring station and the NUS atmospheric research station). When SidePak was used to measure the 1-hour $\mathrm{PM}_{2.5}$ exposure at the bus stop (ME4), the measured concentrations were 3.3, 1.7, and 4.8 times higher than those observed at the nearby fixed monitoring station during the morning, afternoon, and evening hours, respectively. The BC concentration observed at ME4 was generally 3.1 times higher than that measured by the AE33 instrument located at the NUS atmospheric research station over the entire measurement period. Thus, the current results suggest that the personal exposure assessment has the potential to provide the public-health-relevant data at the city scale through the participation of volunteers.
Outdoor Smoking Area (ME1)

While mainstream tobacco smoke is a direct concern for smokers, the exhaled and side-stream smoke (known as environmental tobacco smoke [ETS]) contributes to passive smoking. Exposure to ETS has been associated with adverse health outcomes in adults and children, such as asthma, respiratory infection, and lung cancer (Hill et al., 2004; Yolton et al., 2004). Smoking prohibition, first introduced in 1970, is part of the national effort to promote a smoke-free lifestyle in Singapore. However, there are still certain designated smoking areas in the country (around 900 smoking corners island-wide; Alfred, 2018). To date, limited data have been published in the archival literature on the assessment of human exposure to outdoor tobacco smoke. Therefore, we chose ME1 as one of the monitoring 
locations to evaluate the personal exposure to PM in an urban area. The measurement was conducted at a distance within 1-2 $\mathrm{m}$ from smokers. The $\mathrm{PM}_{2.5}$ concentration observed in the outdoor smoking area varied from 14.5 to $140.8 \mu \mathrm{g} \mathrm{m}^{-3}$ with a mean concentration of $55.14 \pm 24.35 \mu \mathrm{g} \mathrm{m}^{-3}$. This mean concentration was 5 times higher than the measured $\mathrm{PM}_{2.5}$ at the background location $\left(11.04 \pm 2.71 \mu \mathrm{g} \mathrm{m}^{-3}\right.$;
Table S4). The measured PM concentration was the lowest in the afternoon compared to other time periods probably due to a decrease in the number of smokers at this smoking area and favorable weather conditions for the dispersion of the cigarette smoke emissions.

The concentration of $\mathrm{BC}$ to $\mathrm{PM}_{2.5}$ was about $18.1 \%$ on average (Fig. 5). The number concentration of UFPs ranged

(a)
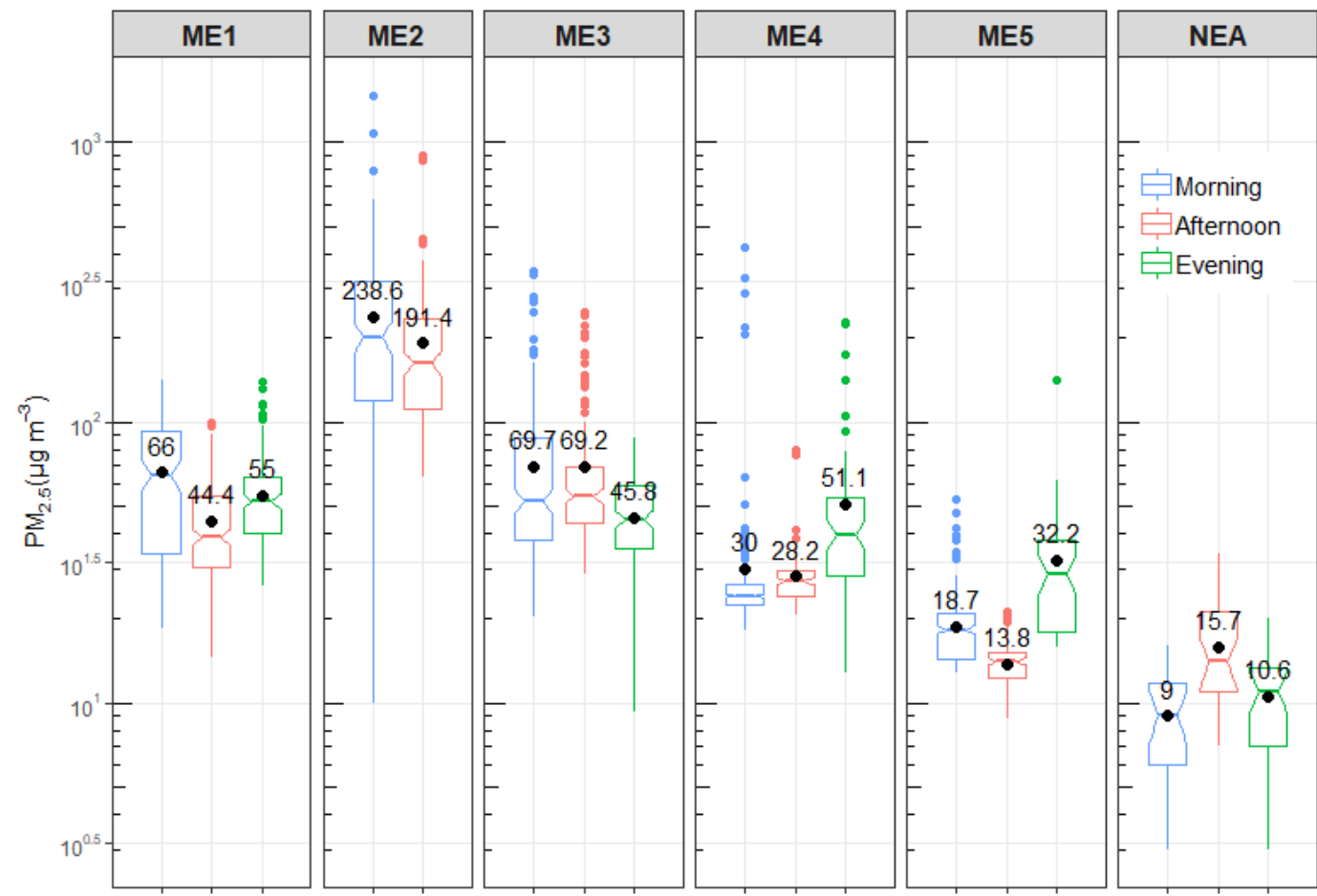

(b)

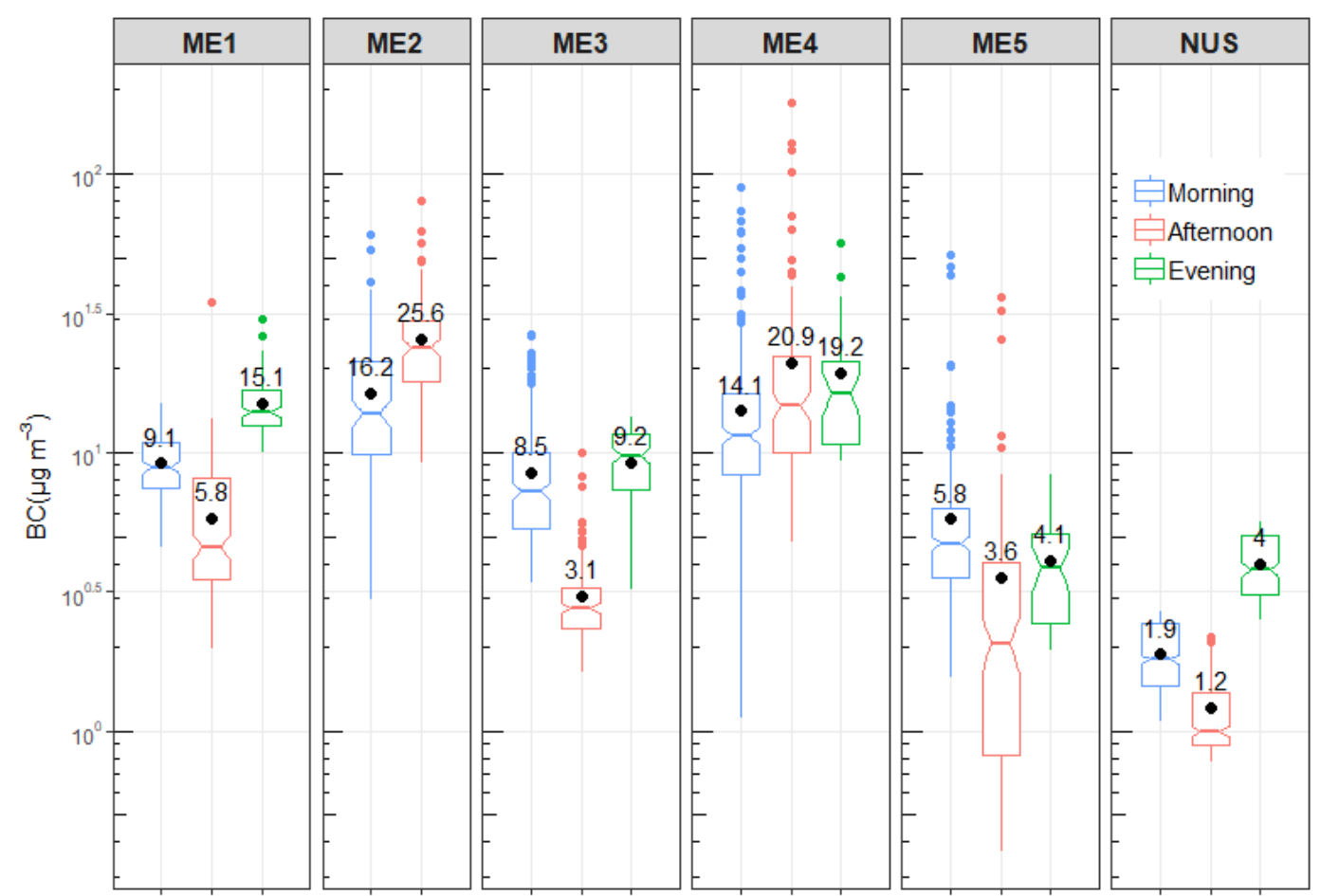

Fig. 4. 1-hour exposure concentrations of (a) $\mathrm{PM}_{2.5}$, (b) BC, (c) $\mathrm{Np}$, and (d) LDSA at selected MEs. These data were compared to those reported by NEA (for $\mathrm{PM}_{2.5}$ ) and NUS laboratory (for $\mathrm{BC}$ ). 
(c)

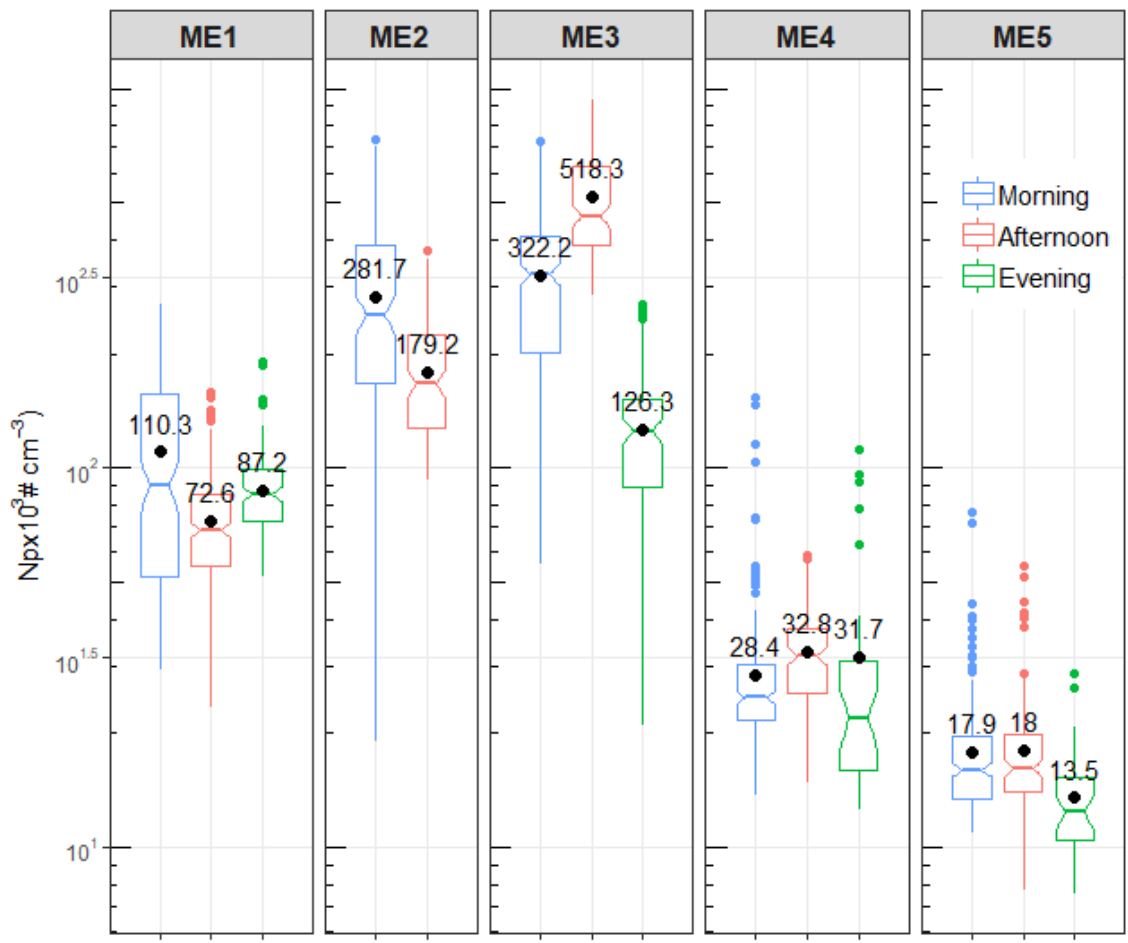

(d)

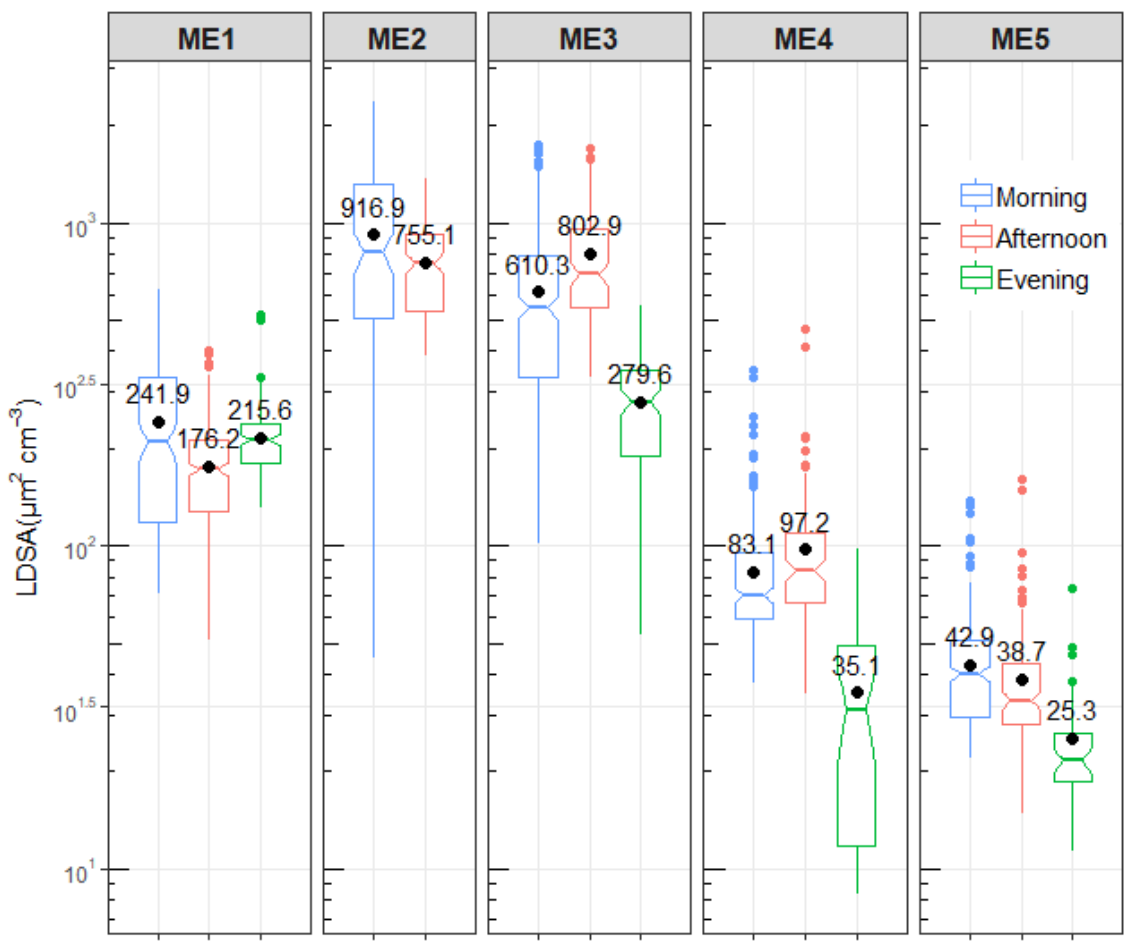

Fig. 4. (continued).

between $23.4 \times 10^{3}$ and $268.7 \times 10^{3} \mathrm{\#} \mathrm{cm}^{-3}$ with a mean concentration of $90.0 \times 10^{3} \pm 38.65 \times 10^{3} \#_{\mathrm{cm}^{-3}}$. In general, the exposure of individuals to PM is highly dependent on the proximity of air pollution sources (Klepeis et al., 2007). Average PM levels within a $0.5-\mathrm{m}$ distance from a smoker were significantly higher while the PM concentrations at a distance greater than $2 \mathrm{~m}$ were much lower and generally close to the background. This observation suggests that pedestrians should avoid spending time in smoking areas and try to move to a distance of greater than $2 \mathrm{~m}$, if unavoidable, to reduce the likelihood of experiencing elevated particle exposure because of tobacco smoke.

\section{Temple (ME2)}

Incense burning, or joss paper burning, is a popular religious practice in Singapore, particularly at Hindu/Buddhist 


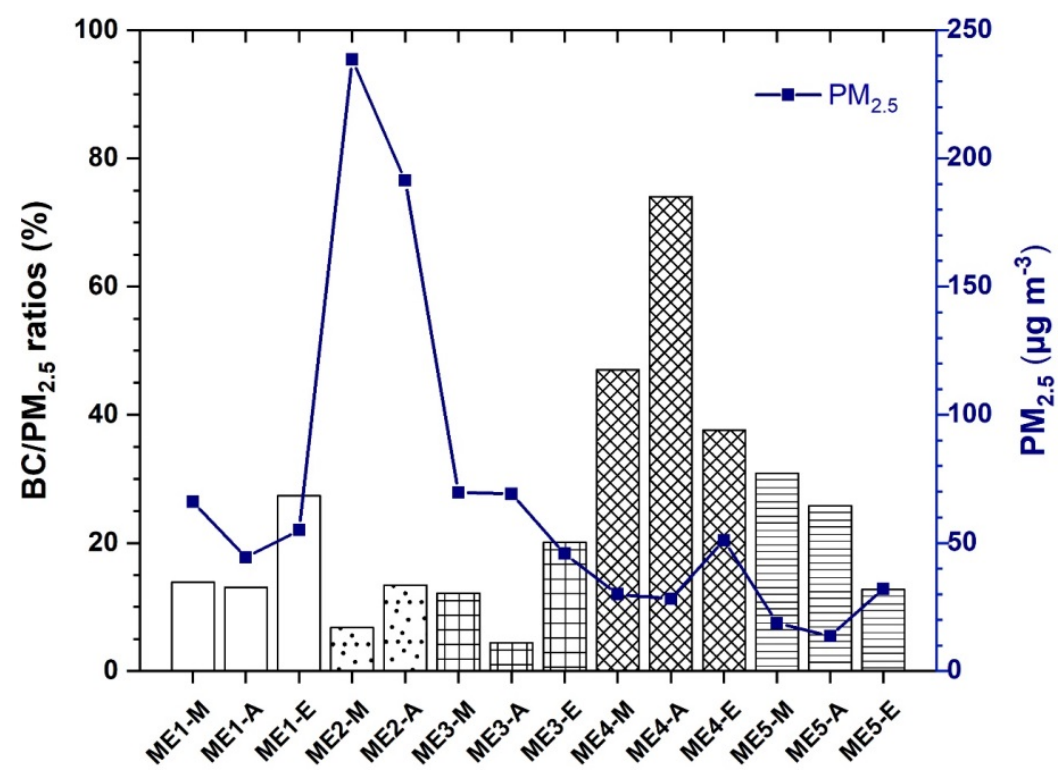

Fig. 5. Ratios of the mean $\mathrm{BC}$ to the mean $\mathrm{PM}_{2.5}$ concentration (\%), and the mean $\mathrm{PM}_{2.5}$ concentration $\left(\mu \mathrm{g} \mathrm{m} \mathrm{m}^{-3}\right)$ at each $\mathrm{ME}$ (M: morning; A: afternoon; and E: evening).

temples. This religious practice produces non-stop heavy smoke due to the nature of its long, slow, and incomplete combustion process. Incense smoke contains $\mathrm{PM}_{2.5}$ and UFPs in large quantities (See et al., 2007; Ji et al., 2010), along with gaseous pollutants including many organic compounds, which are mostly adsorbed onto PM due to their non-volatile or semi-volatile characteristics (Chuang et $a l ., 2013)$. The air pollution in and around various temples has been documented to have severe human health impacts such as respiratory dysfunction, allergy, dermatological effects, and neoplasm (Lin et al., 2008). The mean $\mathrm{PM}_{2.5}$ concentration $\left(215 \pm 129.5 \mu \mathrm{g} \mathrm{m}^{-3}\right)$ observed just outside the temple (ME2) was the highest, which makes this location the leading pollution hotspot compared to the other MEs. This mean concentration was about 20 times higher than the measured $\mathrm{PM}_{2.5}$ at the background location. At this $\mathrm{ME}$, the contribution of $\mathrm{BC}$ to $\mathrm{PM}_{2.5}$ was about $10.1 \%$ on average (shown in Fig. 5). For UFPs, the number concentration varied between $19 \times 10^{3}$ and $734 \times 10^{3} \#$

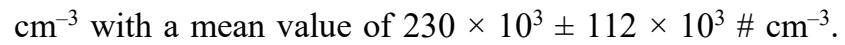
This variation is attributed to changes in the number of devotees visiting the temple and the number of incense sticks burnt in the temple. In general, the number of devotees was higher in the morning hours ( 09:00-10:00) compared to the afternoon hours $(\sim 12: 00-13: 00)$. This pattern leads to higher particle levels measured inside the temple during the morning hours. The particle levels inside the temple were reported to be much higher (18 times, based on the study of Lin et al. (2002)) than what was measured outside the temple. Exposure to incense smoke is of health concern and should be reduced as much as possible. The emission of air pollutants from incense smoke can be effectively reduced by using less pollutive incense sticks (e.g., nanoscale calcium carbonate (Yang et al., 2011) and keeping sufficient indoor ventilation. Moreover, people should shorten the exposure time when they worship at the temple when the incense smoke is heavy to reduce the risk of exposure to toxic PM.

\section{Hawker Center (ME3)}

Hawker centers or food courts are an open-air complex that houses many food stalls selling a variety of ethnic food including Chinese, Malay, Indian, and Western food. Hawker centers are a unique feature of Singaporean culture and lifestyle. There are currently more than 100 hawker centers with more than 6000 food stalls located all over Singapore (MEWR-Singapore, 2017). It is well known that the emission of PM from cooking activities is strongly influenced by the type of stoves used, cooking styles, lipid contents in the food, and the quantities of food cooked and ingredients used (Lee et al., 2001; See and Balasubramanian, 2008). In Singapore, liquefied petroleum gas is used as the primary source of energy for cooking. Therefore, food cooking using gas stoves is considered to be a significant source of airborne particles, especially UFPs, in many commercial kitchens, located in different parts of Singapore. Also, stir-frying and deep-frying are the commonly used cooking methods in different food stalls in Singapore. This cooking approach is found to produce more PM than other cooking methods (See and Balasubramanian, 2006).

The mean $\mathrm{PM}_{2.5}, \mathrm{BC}$, and UFP concentrations observed at the hawker center were $61.6 \pm 38.7 \mu \mathrm{g} \mathrm{m}^{-3}, 6.9 \pm 2.9 \mu \mathrm{g} \mathrm{m}^{-3}$, and $320.8 \times 10^{3} \pm 131.1 \times 10^{3} \# \mathrm{~cm}^{-3}$, respectively. Higher PM concentrations were recorded in the morning and afternoon compared to the evening hours because intensive cooking takes place to prepare breakfast and lunch. The exposure to PM from cooking activities was not confined only to the kitchen, and airborne particles were quickly dispersed to other places including the eating areas as revealed by our personal exposure measurements. Even though the concentration of PM should be lower in these 
places than that in the kitchen corner, the measured $\mathrm{PM}_{2.5}$ and UFPs concentrations at the dining table were 5.6 and 19.0 times higher than those in the background location, respectively (given in Table S4). These high particle concentrations, especially with UFPs, makes the hawker center a pollution hotspot compared to the other MEs. In a previous study conducted in Singapore (See and Balasubramanian, 2006), the levels of non-carcinogenic and carcinogenic risk were 1.54 and 111 times higher than the acceptable levels, respectively. Effective protective measures should, therefore, be undertaken to reduce cooking fumes and minimize human exposure to such particulate emissions. Using electric stoves instead of gas stoves, avoiding cooking at very high temperature, and keeping exhaust fan on during cooking may prove to be effective in reducing the exposure to PM derived from commercial cooking. Moreover, the use of particulate control devices with a high removal efficiency of PM will also be useful to mitigate the health effects of PM released from cooking.

\section{Bus Stop (ME4) and Traffic Intersection (ME5)}

The mean $\mathrm{PM}_{2.5}$ concentrations measured at the bus stop (ME4) and at the traffic intersection (ME5) were 36.4 \pm 12.5 and $21.5 \pm 5.5 \mu \mathrm{g} \mathrm{m}^{-3}$ during the study periods. However, the $\mathrm{PM}_{2.5}$ concentrations can go up to $50-400 \mu \mathrm{g} \mathrm{m}^{-3}$ during the acceleration or deceleration of on-road vehicles approaching or leaving the bus stop or traffic intersection. The

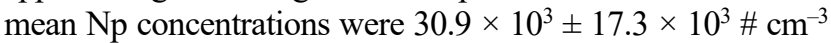

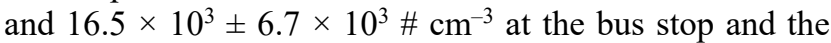
traffic intersection, respectively. These PM concentrations are comparable to those measured in similar studies in other highly populated cities such as Taipei, Taiwan (Lung et al., 2014); Florence, Italy (Fondelli et al., 2008); or Barcelona, Spain (Moreno et al., 2015), at traffic-related locations.

The ratio of the mean $\mathrm{BC}$ to the mean $\mathrm{PM}_{2.5}$, an indicator of the contribution of local incomplete combustion sources to the $\mathrm{PM}_{2.5}$ concentration at each ME, is shown in Fig. 5. In Singapore, 99.7, 81.5, and 2.5\% of the buses, taxis, and passenger cars are powered by diesel (LTA-Singapore, 2017). As expected, $B C$ is a significant component of $\mathrm{PM}_{2.5}$ at the measured vehicular-traffic-influenced locations as a product of incomplete diesel combustion. The mean $\mathrm{BC}$ concentrations were elevated to $18.1 \pm 12.0 \mu \mathrm{g} \mathrm{m}^{-3}$ (52.9\% contribution of $\mathrm{BC}$ to $\mathrm{PM}_{2.5}$ ) at the bus stop and 4.5 $\pm 2.1 \mu \mathrm{g} \mathrm{m}^{-3}\left(23.2 \%\right.$ contribution of $\mathrm{BC}$ to $\left.\mathrm{PM}_{2.5}\right)$ at the traffic intersection whereas the mean-BC-to- $\mathrm{PM}_{2.5}$ ratio of other MEs was only $13.5 \%$. The BC fractions observed at traffic-influenced locations in this study are similar to those reported in the previous studies on BC emission from diesel engines (Kirchstetter and Novakov, 2007; Minjares et al., 2014).

\section{Lung-deposited Surface Area Concentrations}

LDSA is considered to be an indicator of the toxicological effects of UFPs (Wittmaack, 2006). In the current study, the mean LDSA values were $213.8 \pm 90.0,834.2 \pm 396.5$, $564.6 \pm 276.5$, and $55.0 \pm 29.4 \mu \mathrm{m}^{2} \mathrm{~cm}^{-3}$ at the outdoor smoking area, the temple, the hawker center, and the traffic-influenced locations, respectively. These values are significantly higher compared to $37.2 \pm 4.2 \mu \mathrm{m}^{2} \mathrm{~cm}^{-3}$ measured at the background location. As expected, LDSA and $\mathrm{Np}$ concentrations followed essentially similar trends as these metrics are related to UFPs. Values of LDSA above $200 \mu \mathrm{m}^{2} \mathrm{~cm}^{-3}$ were generally observed at the hawker center and the temple at any time. The increase in LDSA may be associated with particle-induced adverse health effects (Sinclair and Tolsma, 2004; Buonanno et al., 2013). The LDSA concentration was found to vary between 30 and $89 \mu \mathrm{m}^{2} \mathrm{~cm}^{-3}$ at the urban background measurement stations located in Los Angeles, USA (Ntziachristos et al., 2007); Barcelona, Spain (Reche et al., 2015); and Lisbon, Portugal (Gomes et al., 2012). Although not directly comparable, our present results had a similar order of magnitude at the urban background site (a mean LDSA of $37.2 \pm 4.2 \mu \mathrm{m}^{2} \mathrm{~cm}^{-3}$ ). To the best of our knowledge, limited measurements of LDSA were conducted at different indoor and outdoor MEs in urban areas.

\section{Measurement-based 24-hour Exposure Risk Assessment}

24-hour $\mathrm{PM}_{2.5}$ personal exposure monitoring was conducted by the two subjects over 4 days recording their time activity patterns as illustrated in Fig. 6. This figure shows a representative integrated 24-hour exposure conducted on 3 Nov. 2017. The $\mathrm{PM}_{2.5}$ concentrations measured with the portable device were compared to those obtained from the fixed ambient air monitoring station maintained by the NEA for 4 days. For this comparison, an inhalation rate of $1.3 \times$ $10^{-2} \mathrm{~m}^{3} \mathrm{~min}^{-1}$ was assumed based on the recommendation made by Moya et al. (2011). To the best of our knowledge, integrated 24-hour assessment of personal exposure to $\mathrm{PM}_{2.5}$ has been sparsely reported in the literature. We compared the results obtained from this study (Table 2) to those reported by Cao and Thompson (2017) and Assimakopoulos et al. (2018). Our present results indicate a higher particle dosage to the respiratory system as compared to the aforementioned studies which is attributed to the differences in time-activity patterns, physical health factors (e.g., gender, age, height, and body weight), intensity of human activity levels (e.g., sitting, walking, or cycling), and the time, duration, extent, and severity of exposure to $\mathrm{PM}_{2.5}$. Higher particle deposition fraction has been reported among children or the elderly than among healthy adults with the same PM exposure level (Moya et al., 2011), and this can in turn lead to more adverse health impacts to the former due to their weak immune systems.

The toxicological health risk associated with exposure to $\mathrm{PM}_{2.5}$ was estimated in the current study. The estimated risk quotient (RQ) value is 3.3 (Table 3 ) when the exposure duration (ED) was assumed as 70 years as the worst-case scenario (Cal/EPA, 2003; LAX, 2014; Cal/EPA, 2015). It should be noted that the estimated potential noncarcinogenic health risk would be lower $(\mathrm{RQ}=1.4)$ if the ED for adults is to be taken as 30 years at the MEIR (maximally exposed individual resident). A value of RQ greater than 1 is indicative of potential adverse health effects on the exposed human population. The estimated chronic non-carcinogenic health risk shows clearly that 


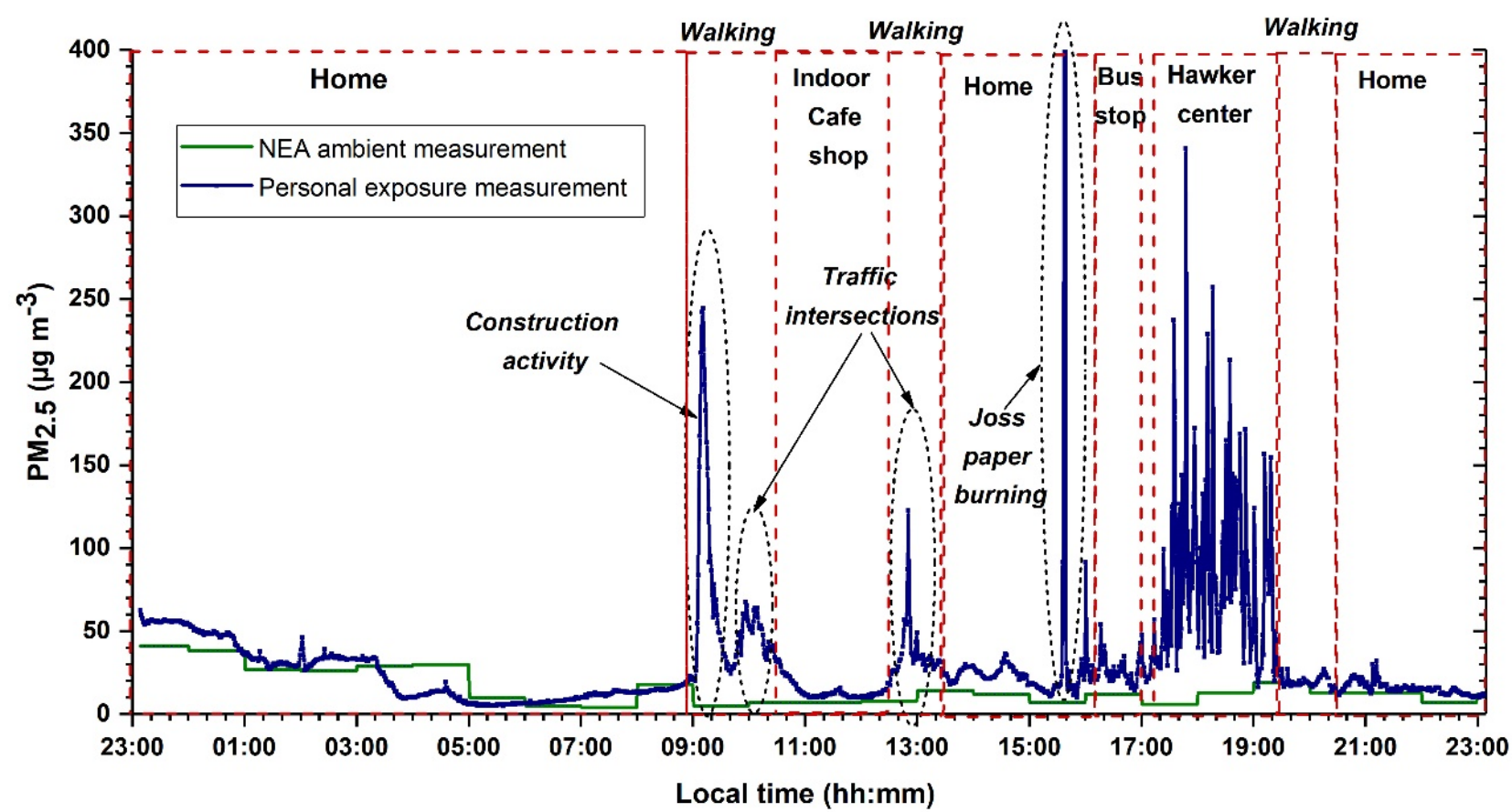

Fig. 6. 24-hour integrated exposure to $\mathrm{PM}_{2.5}$. The measurement was conducted on 3 Nov. 2017.

Table 2. 24-hour integrated inhaled dose of $\mathrm{PM}_{2.5}$ based on personal exposure and ambient outdoor air quality monitoring.

\begin{tabular}{llll}
\hline \multirow{2}{*}{ Monitoring day } & \multicolumn{3}{c}{ 24-hour integrated inhaled dose of $\mathrm{PM}_{2.5}(\mu \mathrm{g})$} \\
\cline { 2 - 4 } & $\begin{array}{l}\text { Personal exposure } \mathrm{PM}_{2.5} \\
\text { monitoring }\end{array}$ & $\begin{array}{l}\text { Ambient outdoor } \mathrm{PM}_{2.5} \\
\text { monitoring }\end{array}$ & $\begin{array}{l}\text { Personal exposure/ambient } \\
\text { outdoor ratios }\end{array}$ \\
\hline Day 1 & 608.5 & 337.0 & 1.8 \\
Day 2 & 725.3 & 468.0 & 1.5 \\
Day 3 & 755.0 & 430.3 & 1.8 \\
Day 4 & 586.2 & 280.8 & 2.1 \\
\hline
\end{tabular}

Table 3. Results of health risk assessment.

\begin{tabular}{lll}
\hline Factors & Value & Unit \\
\hline Average integrated concentration of $\mathrm{PM}_{2.5}(\mathrm{CA})$ & 35.7 & $\mu \mathrm{m} \mathrm{m}^{-3}$ \\
Lifetime average daily dose (LADD) & 4.4 & $\mu \mathrm{kg}^{-1} \mathrm{day}^{-1}$ \\
Reference dose (RfD) & 1.3 & $\mu \mathrm{g} \mathrm{kg}^{-1} \mathrm{day}^{-1}$ \\
Risk quotient (RQ) & 3.3 & - \\
\hline
\end{tabular}

individuals exposed to $\mathrm{PM}_{2.5}$ and the particulate-bound toxic components derived from diverse outdoor and indoor MEs in densely populated countries such as Singapore may experience adverse health outcomes over their lifetime, resulting in a reduction in their life expectancy. The RQ estimated for adults was 1.15 in urban Mexico City (Díaz and Dominguez, 2009), whereas that of children under the age of 8 was 2.23 in the Brazilian Amazon region (de Oliveira et al., 2012). Our results, therefore, corroborate other studies conducted elsewhere which found that the long-term inhalation of elevated levels of PM was associated with lung hyperinflation, indicative of small airway, cardiovascular, and neurological diseases (Calderon-Garciduenas et al., 2000; Heal et al., 2012; Landrigan et al., 2018). For estimation of carcinogenic health risk, the chemicals that are adsorbed onto airborne particles such as PAHs and toxic metals such as $\mathrm{Cr}$ (VI), $\mathrm{Zn}$, and $\mathrm{Pb}$ should be considered. Inhalable PM containing such chemicals can be deposited deep in the interior part of human lungs (Zwozdziak et al., 2017).

The 24-hour $\mathrm{PM}_{2.5}$ concentrations obtained from the personal sampler and the ambient $\mathrm{PM}_{2.5}$ monitor showed a poor correlation $\left(\mathrm{R}^{2}=0.025\right)$, indicating that the conventional $\mathrm{PM}_{2.5}$ measurements made at fixed air quality monitoring stations are not representative of personal exposure to $\mathrm{PM}_{2.5}$ and therefore cannot be used for health risk estimates. Conversely, short-term personal exposure measurements reveal that the health risk estimate obtained from the true exposure to $\mathrm{PM}_{2.5}$ is higher than that predicted by outdoor ambient $\mathrm{PM}_{2.5}$ data (i.e., the ratio of $\mathrm{PM}_{2.5}$ measured for personal exposure to that measured at fixed monitoring stations $\geq 1.5$; Table 2 ). The personal exposure level and 
its potential health outcomes depend on various factors, including existing health conditions of exposed individuals; the intensity of physical activities, such as walking and cycling; the time, place, duration, and severity of exposure; the nature of PM emission sources to which the individual is exposed; and the size, quantity, and chemical compositions of PM.

\section{PRACTICAL IMPLICATIONS}

Elevated concentrations of $\mathrm{PM}_{2.5}$, especially $\mathrm{BC}$, were observed at transport-influenced MEs in Singapore, making them hotspots of PM emissions in the outdoor environment. The personal exposure to $\mathrm{PM}_{2.5}$ in such MEs is, therefore, of health concern. Even a short-term exposure to $\mathrm{PM}_{2.5}$ in such pollution hotspots can contribute substantially to the daily personal exposure and related health effects. A better design of bus stops (e.g., bus shelters that minimize trapping of air pollutants) and/or relocation of bus stops away from busy traffic intersections may reduce the personal exposure to freshly emitted airborne particles of vehicular origin. In the long term, significant mitigation of particulate emissions from automobiles, especially from diesel vehicles; substantial investments in electric mobility; and promotion of active modes of transport, such as walking, and cycling, can lead to enhancement of urban air quality in Singapore with health benefits. The assessment of personal exposure to UFPs in terms of the LDSA concentration indicated that the food court and the temple are the PM hotspots. Therefore, appropriate PM exposure mitigation measures should be implemented at these MEs. Overall, this study emphasizes the need of conducting integrated personal exposure assessment over 24 hours across urban micro-environments together with the recording of individual time-activity patterns. Such a comprehensive personal exposure assessment can indeed complement the fixed-site PM measurements in the context of health risk assessment and long-term public health improvement.

\section{CONCLUSIONS}

The personal exposure to $\mathrm{PM}_{2.5}, \mathrm{BC}$, and UFPs was measured in the CBD area of Singapore, and the LDSA concentration, an indicator of the health impacts of UFPs, was estimated. The level of exposure was assessed along a 7-km walking route to identify air pollution hotspots, and the concentrations were then monitored for 1 hour at each of the five hotspots. T, RH, and GPS data were also recorded during the personal exposure monitoring campaign. The $\mathrm{PM}_{2.5}$ mass concentration varied from 22.2 to $46.2 \mu \mathrm{g} \mathrm{m}^{-3}$, with a mean of $32.5 \mu \mathrm{g} \mathrm{m}^{-3}$, over the route, with $24.5 \%$ of it, on average, contributed by BC. Based on the measurements, the mean Np and LDSA concentrations were $62.4 \times 10^{3} \# \mathrm{~cm}^{-3}$ and $125.5 \mu^{2} \mathrm{~cm}^{-3}$, respectively, along the route. Extremely high concentrations of $\mathrm{PM}_{2.5}$ and BC were observed at a temple and a bus stop, and elevated UFP number concentrations and LDSA concentrations identified the hawker center as another hotspot.

Additionally, to evaluate the potential human health risk associated with exposure to $\mathrm{PM}_{2.5}$, 24-hour integrated personal exposure monitoring was conducted for 4 days. The estimated RQ (3.3) indicates a high probability of experiencing negative health effects due to the continual exposure in densely populated cities, which is in agreement with previously reported findings. Moreover, our results reveal that city dwellers are exposed during normal daily activities to urban PM concentrations that exceed those predicted by the most commonly used fixed outdoor air quality monitoring stations.

Although the ambient $\mathrm{PM}_{2.5}$ mass concentrations have been reduced in many developed countries due to the implementation of effective air pollution control policies, more recent PM exposure metrics, such as BC and UFP concentrations, which are considered to be more accurate indicators of potential health outcomes, are seldom investigated in cities. We anticipate that realistic health risk estimates can be calculated and communicated to city dwellers by conducting time-integrated personal exposure measurements across diverse urban MEs in combination with recording individual time-activity patterns and other significant factors. The results of such a comprehensive personal exposure assessment would enable environmental policy makers to identify and implement effective measures for mitigating human exposure to particulate air pollution, leading to increased health benefits for the general public citywide.

This study was primarily conducted to explore the feasibility of assessing the integrated personal exposure to PM across various outdoor and indoor MEs rather than to conclusively measure the concentrations at selected sites. Further research, with an increased number of participants and MEs, is necessary to provide more realistic exposure information on a city scale.

\section{ACKNOWLEDGMENTS}

This research was financially supported by the National Research Foundation (NRF), the Prime Minister's Office, Singapore, under its Campus for Research Excellence and Technological Enterprise (CREATE) program. The authors are grateful to the NRF for financial support from Grant No. R-706-002-101-281.

\section{SUPPLEMENTARY MATERIAL}

Supplementary data associated with this article can be found in the online version at http://www.aaqr.org.

\section{REFERENCES}

Albuquerque, P.C., Gomes, J.F. and Bordado, J. (2012). Assessment of exposure to airborne ultrafine particles in the urban environment of Lisbon, Portugal. J. Air Waste Manage. Assoc. 62: 373-380.

Alfred, C. (2018). Eateries can no longer apply for outdoor smoking areas: NEA, https://www.todayonline.com/singa pore/eateries-can-no-longer-apply-outdoor-smoking-areasnea, Last Access: 1 July 2018. 
Asbach, C., Kaminski, H., Von Barany, D., Kuhlbusch, T.A.J., Monz, C., Dziurowitz, N., Pelzer, J., Vossen, K., Berlin, K., Dietrich, S., Götz, U., Kiesling, H.J., Schierl, R. and Dahmann, D. (2012). Comparability of portable nanoparticle exposure monitors. Ann. Occup. Hyg. 56: 606-621.

Assimakopoulos, V.D., Bekiari, T., Pateraki, S., Maggos, T., Stamatis, P., Nicolopoulou, P. and Assimakopoulos, M.N. (2018). Assessing personal exposure to PM using data from an integrated indoor-outdoor experiment in Athens-Greece. Sci. Total Environ. 636: 1303-1320.

Buonanno, G., Marks, G.B. and Morawska, L. (2013). Health effects of daily airborne particle dose in children: direct association between personal dose and respiratory health effects. Environ. Pollut. 180: 246-250.

Cal/EPA (2003). Air toxic hot spots program, guidance manual for preparation of health risk assessments, August 2003, https://oehha.ca.gov/media/downloads/crnr/ hrafinalnoapp.pdf, Last Access: 4 March 2018.

Cal/EPA (2015). Air toxic hot spots program, guidance manual for preparation of health risk assessments, February 2015, https://oehha.ca.gov/media/downloads/cr nr/2015guidancemanual.pdf, Last Access: 4 March 2018.

Calderon-Garciduenas, L., Mora-Tiscareno, A., Chung, C.J., Valencia, G., Fordham, L.A., Garcia, R., Osnaya, N., Romero, L., Acuna, H., Villarreal-Calderon, A., Devlin, R.B. and Koren, H.S. (2000). Exposure to air pollution is associated with lung hyperinflation in healthy children and adolescents in Southwest Mexico City: A pilot study. Inhalation Toxicol. 12: 537-561.

Cao, T. and Thompson, J.E. (2017). Portable, ambient $\mathrm{PM}_{2.5}$ sensor for human and/or animal exposure studies. Anal. Lett. 50: 712-723.

Chan, L.Y., Lau, W.L., Lee, S.C. and Chan, C.Y. (2002). Commuter exposure to particulate matter in public transportation modes in Hong Kong. Atmos. Environ. 36: 3363-3373.

Chuang, H.C., BéruBé, K., Lung, S.C.C., Bai, K.J. and Jones, T. (2013). Investigation into the oxidative potential generated by the formation of particulate matter from incense combustion. J. Hazard. Mater. 244: 142-150.

de Oliveira, B.F.A., Ignotti, E., Artaxo, P., do Nascimento Saldiva, P.H., Junger, W.L. and Hacon, S. (2012). Risk assessment of $\mathrm{PM}_{2.5}$ to child residents in Brazilian Amazon region with biofuel production. Environ. Health Preventative Med. 11: 64.

Delfino, R.J., Sioutas, C. and Malik, S. (2005). Potential role of ultrafine particles in associations between airborne particle mass and cardiovascular health. Environ. Health Perspect. 113: 934-946.

Díaz, R. and Dominguez, E.R. (2009). Health risk by inhalation of $\mathrm{PM}_{2.5}$ in the metropolitan zone of the City of Mexico. Ecotoxicol. Environ. Saf. 72: 866-871.

Dons, E., Int Panis, L., Van Poppel, M., Theunis, J. and Wets, G. (2012). Personal exposure to Black Carbon in transport microenvironments. Atmos. Environ. 55: 392398.

Drinovec, L., Močnik, G., Zotter, P., Prévôt, A.S.H., Ruckstuhl, C., Coz, E., Rupakheti, M., Sciare, J., Müller,
T., Wiedensohler, A. and Hansen, A.D.A. (2015). The "dual-spot" Aethalometer: an improved measurement of aerosol black carbon with real-time loading compensation. Atmos Meas Tech 8: 1965-1979.

Fondelli, M.C., Chellini, E., Yli-Tuomi, T., Cenni, I., Gasparrini, A., Nava, S., Garcia-Orellana, I., Lupi, A., Grechi, D., Mallone, S. and Jantunen, M. (2008). Fine particle concentrations in buses and taxis in Florence, Italy. Atmos. Environ. 42: 8185-8193.

Gakidou, E., Afshin, A., Abajobir, A.A., Abate, K.H., Abbafati, C., Abbas, K.M., et al. (2017). Global, regional, and national comparative risk assessment of 84 behavioural, environmental and occupational, and metabolic risks or clusters of risks, 1990-2016: A systematic analysis for the Global Burden of Disease Study 2016. Lancet 390: 1345-1422.

Gomes, J.F.P., Bordado, J.C.M. and Albuquerque, P.C.S. (2012). On the assessment of exposure to airborne ultrafine particles in urban environments. J. Toxicol. Environ. Health A 75: 1316-1329.

Good, N., Mölter, A., Ackerson, C., Bachand, A., Carpenter, T., Clark, M.L., Fedak, K.M., Kayne, A., Koehler, K., Moore, B., L'Orange, C., Quinn, C., Ugave, V., Stuart, A.L., Peel, J.L. and Volckens, J. (2015). The Fort Collins Commuter Study: Impact of route type and transport mode on personal exposure to multiple air pollutants. $J$. Exposure Sci. Environ. Epidemiol. 26: 397-404.

Govtech-Singapore (2018). https://data.gov.sg/, Last Access: 1 July 2018.

Hagler, G.S.W., Yelverton, T.L.B., Vedantham, R., Hansen, A.D.A. and Turner, J.R. (2011). Post-processing method to reduce noise while preserving high time resolution in aethalometer real-time black carbon data. Aerosol Air Qual. Res. 11: 539-546.

Heal, M.R., Kumar, P. and Harrison, R.M. (2012). Particles, air quality, policy and health. Chem. Soc. Rev. 41: 66066630.

Hill, S., Blakely, T., Kawachi, I. and Woodward, A. (2004). Mortality among "never smokers" living with smokers: Two cohort studies, 1981-4 and 1996-9. BMJ 328: 988989.

Huang, X., Betha, R., Tan, L.Y. and Balasubramanian, R. (2016). Risk assessment of bioaccessible trace elements in smoke haze aerosols versus urban aerosols using simulated lung fluids. Atmos. Environ. 125: 505-511.

ICRP (1994). Human Respiratory Tract Model for Radiological Protection, ICRP Publication 66.

Ji, X., Le Bihan, O., Ramalho, O., Mandin, C., D’Anna, B., Martinon, L., Nicolas, M., Bard, D. and Pairon, J.C. (2010). Characterization of particles emitted by incense burning in an experimental house. Indoor Air 20: 147158.

Kalaiarasan, M., Balasubramanian, R., Cheong, K. and Tham, K. (2009a). Particulate-bound polycyclic aromatic hydrocarbons in naturally ventilated multi-storey residential buildings of Singapore: Vertical distribution and potential health risks. Build. Environ. 44: 418-425.

Kalaiarasan, M., Balasubramanian, R., Cheong, K. and Tham, K. (2009b). Traffic-generated airborne particles 
in naturally ventilated multi-storey residential buildings of Singapore: Vertical distribution and potential health risks. Build. Environ. 44: 1493-1500.

Kaur, S., Nieuwenhuijsen, M. and Colvile, R. (2005). Personal exposure of street canyon intersection users to $\mathrm{PM}_{2.5}$, ultrafine particle counts and carbon monoxide in Central London, UK. Atmos. Environ. 39: 3629-3641.

Kim, K.H., Kabir, E. and Kabir, S. (2015). A review on the human health impact of airborne particulate matter. Environ. Int. 74: 136-143.

Kirchstetter, T.W. and Novakov, T. (2007). Controlled generation of black carbon particles from a diffusion flame and applications in evaluating black carbon measurement methods. Atmos. Environ. 41: 1874-1888.

Klepeis, N.E., Ott, W.R. and Switzer, P. (2007). Real-time measurement of outdoor tobacco smoke particles. J. Air Waste Manage. Assoc. 57: 522-534.

Klompmaker, J.O., Montagne, D.R., Meliefste, K., Hoek, G. and Brunekreef, B. (2015). Spatial variation of ultrafine particles and black carbon in two cities: Results from a short-term measurement campaign. Sci. Total Environ. 508: 266-275.

Koehler, K.A. and Peters, T.M. (2015). New methods for personal exposure monitoring for airborne particles. Curr. Environ. Health Rep. 2: 399-411.

Landrigan, P.J., Fuller, R., Acosta, N.J.R., Adeyi, O., Arnold, R., Basu, N., et al. (2018). The Lancet Commission on pollution and health. Lancet 391: 462-512.

Lee, S.C., Li, W.M. and Chan, L.Y. (2001). Indoor air quality at restaurants with different styles of cooking in metropolitan Hong Kong. Sci. Total Environ. 279: 181193.

Lin, T.C., Krishnaswamy, G. and Chi, D.S. (2008). Incense smoke: Clinical, structural and molecular effects on airway disease. Clin. Mol. Allergy 6: 3 .

Liu, W., Wang, Y., Russell, A. and Edgerton, E.S. (2005). Atmospheric aerosol over two urban-rural pairs in the southeastern United States: Chemical composition and possible sources. Atmos. Environ. 39: 4453-4470.

Liu, W.T., Ma, C.M., Liu, I.J., Han, B.C., Chuang, H.C. and Chuang, K.J. (2015). Effects of commuting mode on air pollution exposure and cardiovascular health among young adults in Taipei, Taiwan. Int. J. Hyg. Environ. Health 218: 319-323.

LAX (Los Angeles International Airport) (2014). Human health risk assessment, March 2014, https://www.lawa.org/ -/media/mscnorth/4_3 msc_deir_human_health_risk_ass essment.ashx?la $=$ en $^{2} \overline{\text { h }}$ ash $=\mathrm{C} 59 \overline{1} \mathrm{~F} 3 \mathrm{~F} 6 \mathrm{E} 5 \mathrm{E} 50 \mathrm{AD} 360 \mathrm{AE}$ 6B798C7276709359C04C, Last Access: 10 September 2018.

LTA-Singapore (2017). Annual Vehicle Statistics 2017, Land Transport Authority.

Lung, S.C.C., Hsiao, P.K., Wen, T.Y., Liu, C.H., Fu, C.B. and Cheng, Y.T. (2014). Variability of intra-urban exposure to particulate matter and $\mathrm{CO}$ from Asian-type community pollution sources. Atmos. Environ. 83: 6-13.

Meier, R., Clark, K., Riediker, M. and Technology (2013). Comparative testing of a miniature diffusion size classifier to assess airborne ultrafine particles under field conditions. Aerosol Sci. Technol. 47: 22-28.

Meteorological Service Singapore (2019). Climate of Singapore, http://www.weather.gov.sg/climate-climateof-singapore/, Last Access: 1 July 2019.

MEWR-Singapore (2017). Hawker Centre 3.0 Committee Report, Ministry of the Environment and Water Resources.

Minjares, R., Wagner, D.V., Baral, A., Chambliss, S., Galarza, S., Posada, F., Sharpe, B., Wu, G., Blumberg, K. and Kamakate, F. (2014). Reducing black carbon emissions from diesel vehicles: Impacts, control strategies, and cost-benefit analysis. The World Bank.

Morales Betancourt, R., Galvis, B., Balachandran, S., Ramos-Bonilla, J.P., Sarmiento, O.L., Gallo-Murcia, S.M. and Contreras, Y. (2017). Exposure to fine particulate, black carbon, and particle number concentration in transportation microenvironments. Atmos. Environ. 157: 135-145.

Moreno, T., Reche, C., Rivas, I., Cruz Minguillón, M., Martins, V., Vargas, C., Buonanno, G., Parga, J., Pandolfi, M., Brines, M., Ealo, M., Sofia Fonseca, A., Amato, F., Sosa, G., Capdevila, M., de Miguel, E., Querol, X. and Gibbons, W. (2015). Urban air quality comparison for bus, tram, subway and pedestrian commutes in Barcelona. Environ. Res. 142: 495-510.

Moya, J., Phillips, L., Schuda, L., Wood, P., Diaz, A., Lee, R., Clickner, R., Birch, R., Adjei, N. and Blood, P. (2011). Exposure factors handbook: 2011 edition. US Environmental Protection Agency.

Ntziachristos, L., Polidori, A., Phuleria, H., Geller, M.D. and Sioutas, C. (2007). Application of a diffusion charger for the measurement of particle surface concentration in different environments. Aerosol Sci. Technol. 41: 571580.

Peters, A., Dockery, D.W., Muller, J.E. and Mittleman, M.A. (2001). Increased particulate air pollution and the triggering of myocardial infarction. Circulation 103: 2810-2815.

Peters, A., von Klot, S., Heier, M., Trentinaglia, I., Hörmann, A., Wichmann, H.E. and Löwel, H. (2004). Exposure to traffic and the onset of myocardial infarction. N. Engl. J. Med. 351: 1721-1730.

Pope, C.A., Dockery, D.W. and Schwartz, J. (1995). Review of epidemiological evidence of health effects of particulate air pollution. Inhalation Toxicol. 7: 1-18.

R Core Team (2018). R: A language and environment for statistical computing. R Foundation for Statistical Computing, Vienna, Austria. 2012. URL http://www. Rproject. org.

Reche, C., Viana, M., Brines, M., Pérez, N., Beddows, D., Alastuey, A. and Querol, X. (2015). Determinants of aerosol lung-deposited surface area variation in an urban environment. Sci. Total Environ. 517: 38-47.

Reynolds, C., Winters, M., Ries, F. and Gouge, B. (2010). Active transportation in urban areas: Exploring health benefits and risks. National Collaboration Centre for Environmental Health 2010: 2.

Rice, M.B., Ljungman, P.L., Wilker, E.H., Gold, D.R., Schwartz, J.D., Koutrakis, P., Washko, G.R., O'Connor, 
G.T. and Mittleman, M.A. (2013). Short-term exposure to air pollution and lung function in the Framingham Heart Study. Am. J. Respir. Crit. Care Med. 188: 13511357.

Rivas, I., Kumar, P., Hagen-Zanker, A., Andrade, M.d.F., Slovic, A.D., Pritchard, J.P. and Geurs, K.T. (2017). Determinants of black carbon, particle mass and number concentrations in London transport microenvironments. Atmos. Environ. 161: 247-262.

Salvi, S., Blomberg, A., Rudell, B., Kelly, F., Sandstrom, T., Holgate, S.T. and Frew, A. (1999). Acute inflammatory responses in the airways and peripheral blood after short-term exposure to diesel exhaust in healthy human volunteers. Am. J. Respir. Crit. Care Med. 159: 702709.

See, S. and Balasubramanian, R. (2006). Risk assessment of exposure to indoor aerosols associated with Chinese cooking. Environ. Res. 102: 197-204.

See, S.W., Balasubramanian, R. and Joshi, U.M. (2007). Physical characteristics of nanoparticles emitted from incense smoke. Sci. Technol. Adv. Mater. 8: 25.

See, S.W. and Balasubramanian, R. (2008). Chemical characteristics of fine particles emitted from different gas cooking methods. Atmos. Environ. 42: 8852-8862.

Sharma, R. and Balasubramanian, R. (2017). Indoor human exposure to size-fractionated aerosols during the 2015 Southeast Asian smoke haze and assessment of exposure mitigation strategies. Environ. Res. Lett. 12: 114026.

Shirmohammadi, F., Sowlat, M.H., Hasheminassab, S., Saffari, A., Ban-Weiss, G. and Sioutas, C. (2017). Emission rates of particle number, mass and black carbon by the Los Angeles International Airport (LAX) and its impact on air quality in Los Angeles. Atmos. Environ. 151: 82-93.

Sinclair, A.H. and Tolsma, D. (2004). Associations and lags between air pollution and acute respiratory visits in an ambulatory care setting: 25-month results from the aerosol research and inhalation epidemiological study. $J$. Air Waste Manage. Assoc. 54: 1212-1218.

Thai, A., McKendry, I. and Brauer, M. (2008). Particulate matter exposure along designated bicycle routes in Vancouver, British Columbia. Sci. Total Environ. 405: 26-35.

Vincent, J.H. (2012). Occupational and environmental aerosol exposure assessment: A scientific journey from the past, through the present and into the future. $J$.
Environ. Monit. 14: 340-347.

Wellenius, G.A., Burger, M.R., Coull, B.A., Schwartz, J., Suh, H.H., Koutrakis, P., Schlaug, G., Gold, D.R. and Mittleman, M.A. (2012). Ambient air pollution and the risk of acute ischemic stroke. Arch Intern. Med. 172: 229-234.

WHO (2012). Health effects of black carbon. World Health Organization, Copenhagen, Denmark.

WHO (2013). Health effects of particulate matter: Policy implications for countries in eastern Europe, Caucasus and Central Asia. WHO Regional Office for Europe, World Health Organisation, Copenhagen, Denmark.

Wilson, J.G. and Zawar-Reza, P. (2006). Intraurban-scale dispersion modelling of particulate matter concentrations: Applications for exposure estimates in cohort studies. Atmos. Environ. 40: 1053-1063.

Wittmaack, K. (2006). In search of the most relevant parameter for quantifying lung inflammatory response to nanoparticle exposure: Particle number, surface area, or what? Environ. Health Perspect. 115: 187-194.

Wu, H., Reis, S., Lin, C., Beverland, I.J. and Heal, M.R. (2015). Identifying drivers for the intra-urban spatial variability of airborne particulate matter components and their interrelationships. Atmos. Environ. 112: 306316.

Yang, C.R., Peng, Y.S., Chang, Y.F. and Tsai, Y.I. (2011). Reducing emissions of air pollutants from incense burning with the addition of nanoscale calcium carbonate. Sci. Res. Essays 6: 2011-2018.

Yolton, K., Dietrich, K., Auinger, P., Lanphear Bruce, P. and Hornung, R. (2005). Exposure to environmental tobacco smoke and cognitive abilities among US children and adolescents. Environ. Health Perspect. 113: 98103.

Zwozdziak, A., Gini, M.I., Samek, L., Rogula-Kozlowska, W., Sowka, I. and Eleftheriadis, K. (2017). Implications of the aerosol size distribution modal structure of trace and major elements on human exposure, inhaled dose and relevance to the $\mathrm{PM}_{2.5}$ and $\mathrm{PM}_{10}$ metrics in a European pollution hotspot urban area. J Aerosol Sci 103: $38-52$. 